\title{
Los corredores ecológicos y su importancia ambiental: Propuestas de actuación para fomentar la permeabilidad y conectividad aplicadas al entorno del río Cardeña (Ávila y Segovia)
}

\author{
Fernando GARCÍA QUIROGA \\ Director Adjunto \\ Gabitea Medio Ambiente \\ nancht@gmail.com \\ Jesús ABAD SORIA \\ Técnico y asesor de proyectos ambientales \\ Gabitea Medio Ambiente \\ jabadsaga@gmail.com
}

Recibido: 5 de junio de 2014

Enviado a evaluar: 26 de junio de 2014

Aceptado: 6 de octubre de 2014

\section{RESUMEN}

Los corredores ecológicos amparados en nuestra legislación estatal, constituyen nexos de unión entre espacios con altos valores ambientales independientemente del ámbito territorial en el que se encuentren. Es el caso del río Cardeña que une dos espacios incluidos en la Red Natura 2000 situados entre las provincias de Ávila y Segovia. Pero para garantizar su capacidad de interconectar diferentes áreas, es necesario reducir los impactos que pueden sufrir actualmente o que pueden constituir una amenaza futura. Para ello, es necesario implantar una serie de actuaciones que garanticen y mejoren las funciones ecológicas, que a su vez supondrán un beneficio social tanto a corto como sobre todo a medio y largo plazo.

Palabras clave: Corredor ecológico, conectividad, Red Natura 2000, fragmentación de hábitats.

The ecological corridors and their environmental importance:

Action proposals to promote permeability and connectivity applied to the

Cardeña river surroundings (Ávila and Segovia)

\begin{abstract}
Ecological corridors sheltered by our state laws, constitute links between areas with high environmental values regardless of the territorial scope in which they are. This is the case of the Cardeña River which links two areas included in the Natura 2000 network located between the provinces of Ávila and Segovia. But to ensure its capacity to interconnect different areas, it is necessary to reduce the impacts that they may experience now or that may constitute a future threat. For this, it is necessary to implement a series
\end{abstract}


of actions to ensure and improve the ecological functions, which in turn will mean a social benefit in the short and especially medium and long term.

Key words: ecological corridor, conectivity, Natura 2000 network, hábitat fragmentation.

Les corridors écológiques et leur importance environnementale: Propositions d'action visant á promouvoir la perméabilité et connectivité concernant les abords de la rivière de Cardeña

\section{RÉSUMÉ}

Les corridors écologiques couverts par la législation d'État, sont des liens entre les espaces à haute valeur environnementale quel que soit le cadre territorial dans lequel ils se trouvent. C'est le cas de la rivière de Cardeña qui unit deux sites du réseau Natura situés entre les provinces d'Avila et Ségovie. Mais, pour garantir leur capacité d'interconnexion entre les différents espaces, il est nécessaire de réduire les impacts qui peuvent subir actuellement ou ceux qui peuvent constituer une menace dans le futur. $\mathrm{C}^{\prime}$ est pour ça qu'il convient de prévoir toute une série d'actions qui garantissent et améliorent les fonctions écologiques, ce qui entraînera des bénéfices sociaux à court terme mais surtout à moyen et long terme.

Mots clés: corridor écologique, connectivité, réseau Natura 2000, fragmentation des habitats.

\section{INTRODUCCIÓN}

Las obstrucciones antropogénicas han favorecido la falta de "comunicación ecológica" (Tillmann, 2005), debido a los cambios de uso del suelo que afectan en gran medida a la capacidad de dispersión de las especies, dando lugar a procesos de fragmentación de las poblaciones y a los consiguientes problemas para su conservación, en todo el mundo. Garantizar la conectividad entre "parches" o "islas" de diferentes hábitats es importante, tanto para la dispersión de especies como para la protección de los propios hábitats (Fahrig, 2003). Los conjuntos de espacios naturales protegidos tienden en la actualidad a constituirse legalmente como redes de conservación. La preservación de la conectividad y la integridad ecológica de la red de espacios naturales Natura 2000 es, además, un requisito legal impuesto por la Directiva Hábitats.

En efecto, la pérdida de hábitat y la fragmentación se consideran una de las principales amenazas que afectan a la diversidad biológica, lo que supone que la fragmentación de los hábitats sea una de las principales causas de extinción de especies. Mientras que la pérdida de hábitat es difícilmente solucionable, ya que en muchos casos es consecuencia de demandas territoriales para el crecimiento urbano, la expansión agrícola, o el uso para determinadas actividades productivas o industriales. El problema de la conectividad tiene una solución más "sencilla", ya que en ocasiones una solución eficaz no implica grandes demandas de superficie sino continuidad y coherencia territorial.

Los corredores ecológicos son espacios que conectan áreas de importancia biológica para mitigar los impactos negativos provocados por la fragmentación de los 
hábitats (Conrad et al., 2011). El desarrollo de la conectividad a través de corredores ecológicos resulta fundamental para la biodiversidad y también para asegurar el intercambio genético y energético a través de una mayor extensión geográfica (Roy et al., 2010). El concepto de corredor ecológico está vinculado a contextos científicos y sociales. Durante las últimas décadas han aparecido muchos datos sobre la importancia de los corredores ecológicos para superar el problema de la fragmentación territorial (Van and Sawart, 2008).

No debe pensarse únicamente en la idea de corredores como estructuras lineales más o menos estrechas que conectan dos espacios. Particularmente, en el paisaje mediterráneo persiste un mosaico heterogéneo formado por coberturas del suelo con grados intermedios de intervención o incluso espacios "en rosario" con hábitats bien conservados, que pueden tener especial importancia en la conectividad, desde una visión más global destacando la capacidad del territorio para favorecer flujos de especies o conjuntos de éstas por el paisaje. Desde una visión más integradora, la conectividad puede resultar de una conexión física o estructural derivada de las habilidades de las especies, para moverse por los distintos elementos del paisaje.

El análisis y planificación territorial para asegurar el paso seguro de la fauna silvestre, implica la comprensión de las complejidades de los paisajes naturales y humanos, así como la incorporación de las evaluaciones de conectividad en la planificación local y regional (Patrick et al., 2012). A pesar de que pueda tener lo enunciado la lógica necesaria como para la implantación de diferentes actuaciones enmarcadas en la ampliación de la mejora ecológica de los territorios, pocas son las actuaciones efectuadas en nuestro país, entendidas en el ámbito de mejorar la conectividad del territorio, evitando de esta manera su fragmentación. Existen algunos ejemplos en el País Vasco, Murcia, Cataluña o de manera más tenue en la Comunidad de Madrid, si bien, claros ejemplos enfocados para minimizar el fraccionamiento de un área lo constituyen los pasos de fauna realizados en algunas de las múltiples nuevas infraestructuras del transporte terrestre que han proliferado a pesar de su dudosa rentabilidad económica y social por toda la geografía nacional. Además, en el caso de los Lugares de Importancia Comunitaria (LICs) muchos de ellos por su carácter lineal, han sido diseñados para garantizar la conectividad ecológica de uno o más espacios naturales. Pero no solamente el ámbito de los LICs debe ser objeto de medidas específicas, también las áreas de conectividad, hoy denominadas más comúnmente como corredores ecológicos que apenas han sido delimitados y estudiados.

De esta manera las áreas de conectividad o corredores ecológicos podrían ser definidos como franjas más o menos anchas de territorio que permiten el mantenimiento de biotopos naturales de manera longitudinal y que conectan espacios de interés o relevancia ambiental, conformando espacios integrados en red dignos de ser preservados con la adecuada regulación que permitiese un uso sostenible de los mismos, si bien prevaleciendo su funcionalidad ecológica como elemento de conectividad de hábitats y ecosistemas para favorecer la dispersión de los seres vivos $\mathrm{y}$, por ende, como instrumento para fomentar la biodiversidad. 
Existen dos formas principales de promover la conectividad del paisaje:

a) La gestión integral del conjunto de mosaicos del paisaje para facilitar el movimiento y la continuidad de las poblaciones.

b) La gestión específica de hábitats dentro del paisaje mediante la gestión de corredores continuos entre estos hábitats naturales. Como ejemplos de estos corredores pueden citarse los linderos en determinados paisajes agrícolas, los cauces y riberas de los ríos, las masas boscosas más o menos lineales de vegetación forestal y, en España, las vías pecuarias.

Se usa el término corredor ecológico de forma genérica para expresar una vía que facilita la dispersión de los seres vivos a través de hábitats (u otros elementos o procesos de interés) que conectan dos o más lugares, en los cuales encuentran condiciones adecuadas para su desarrollo.

La contribución de las áreas protegidas a la conservación del conjunto del territorio requiere de una planificación de carácter integrador. Para ello es necesario, entre otros aspectos, potenciar la conservación y el uso sostenible de la biodiversidad de determinadas áreas, no necesariamente protegidas, que puedan actuar de corredor ecológico y permitan la comunicación entre espacios para el intercambio genético de flora y fauna.

Los principales efectos potenciales positivos que generan las áreas de conectividad o corredores ecológicos (Noss 1993; McEuen 1993; Bennett 1999; Gurrutxaga San Vicente \& Lozano Valencia 2008) son:

- Facilitan los desplazamientos de la fauna a través de paisajes transformados.

- Benefician la gran diversidad de especies, como las que presentan grandes áreas de campeo, las migratorias o las multihábitat.

- Aumentan las tasas de inmigración de individuos de especies sensibles a la fragmentación en las fracciones de hábitat.

- Disminuyen el aislamiento de las poblaciones locales.

- Favorecen el intercambio genético interpoblacional y la variabilidad genética, al tiempo que previenen fenómenos de endogamia y deriva genética.

- Facilitan la suplementación de poblaciones pequeñas en declive, de forma que se frenan las tendencias a la extinción local.

- Permiten la recolonización de hábitats y el restablecimiento de poblaciones tras episodios de extinción local.

- Favorecen el mantenimiento de mayor riqueza y diversidad de especies nativas en los fragmentos de hábitat.

- Proveen de hábitat, refugio y otros recursos necesarios, a numerosas especies silvestres.

- Aumentan la diversidad paisajística.

Las zonas de interconexión que podrían conformar corredores ecológicos, implica a ámbitos como los siguientes: 
- Los espacios forestales o montes de titularidad pública, sean o no de Utilidad Pública, y estén o no incluidos en la Red Natura 2000, así como los Montes Protectores, de titularidad privada.

- Hábitats de Interés Comunitario que no están bajo figuras de protección, ya sean LIC, ZEC, ZEPA, u otras.

- El sistema fluvial y los terrenos de dominio público hidráulico y policía, así como aquellos otros, asociados, funcional y paisajísticamente, a los principales cursos fluviales que se consideren de interés estratégico para la configuración, continuidad y funcionamiento del sistema de espacios abiertos. También los asociados al sistema de embalses y otros espacios húmedos, protegidos o no por la legislación.

- Las vías pecuarias, que suponen una estructura lineal territorial válida para la interconexión de los espacios naturales protegidos.

- Los paisajes agrícolas y ganaderos (matorrales, setos, pastizales, etc).

\section{LOS CORREDORES ECOLÓGICOS EN EL CONTEXTO LEGISLATIVO EUROPEO Y ESPAÑOL}

La idea central de Natura 2000 es la de constituir una Red de espacios naturales protegidos dentro de la Unión Europea establecida con arreglo a la Directiva 92/43 CEE del Consejo, de 21 de mayo de 1992, relativa a la conservación de los hábitats naturales y de la fauna y flora silvestres. Incluye, asimismo, los parajes declarados en virtud de la Directiva 79/409/CEE del Consejo, de 2 de abril de 1979, hoy reemplazada por la Directiva 2009/147/CE del Parlamento Europeo y del Consejo de 30 de noviembre de 2009 relativa a la conservación de las aves silvestres. La red tiene por objeto garantizar la supervivencia a largo plazo de las especies y hábitats europeos más valiosos y amenazados.

La necesidad de una red de estas características se hizo patente ante la destrucción y fragmentación a gran escala que durante décadas estaban sufriendo los hábitats naturales, situación que pretendía ser paliada por la Red Ecológica Paneuropea (PEEN) vinculada directamente y especialmente en sus aspectos operativos o funcionales a la Red Natura 2000 y la Directiva Hábitat, la cual se centra específicamente en salvaguardar la coherencia de la Red Natura 2000, como un red adecuada de espacios ecológicos en nodos que se corresponden con los LIC/ZEC y ZEPA, y conectores y/o corredores que permitan el flujo de energía y/o materia en y entre los nodos.

La Directiva 92/43/CEE señala en el apartado 1 del artículo 3 que la Red Natura 2000 es "una red ecológica europea coherente de zonas especiales de conservación", y en el apartado 3 del artículo 3, establece que "cuando lo consideren necesario, los Estados miembros se esforzarán por mejorar la coherencia ecológica de Natura 2000 mediante el mantenimiento y, en su caso, el desarrollo de los elementos del paisaje 
que revistan primordial importancia para la fauna y la flora silvestres que cita el artículo 10".

Sobre este mismo aspecto de la coherencia ecológica de la red, se insiste en el artículo 10, indicando:

"Cuando lo consideren necesario, los Estado miembros, en el marco de sus políticas nacionales de ordenación del territorio y de desarrollo, y, especialmente, para mejorar la coherencia ecológica de la red Natura 2000, se esforzarán por fomentar la gestión de los elementos del paisaje que revistan primordial importancia para la fauna y la flora silvestres.

Se trata de aquellos elementos que, por su estructura lineal y continua (como los ríos con sus correspondientes riberas o los sistemas tradicionales de deslinde de los campos), o por su papel de puntos de enlace (como los estanques o los sotos) resultan esenciales para la migración, la distribución geográfica y el intercambio genético de las especies silvestres".

En definitiva se plantea la coherencia como cohesión ecológica y de sus hábitats para, fundamentalmente, evitar la fragmentación de hábitats y garantizar su conectividad.

Asimismo, en el artículo 6 de la Directiva, en el que se hace referencia a los planes y proyectos que puedan afectar a espacios de la red, se señala expresamente en el apartado 4 que:

"Si debiera realizarse un plan o proyecto por razones imperiosas de interés público de primer orden, incluidas razones de índole social o económica, el Estado miembro tomará cuantas medidas compensatorias sean necesarias para garantizar que la coherencia global de Natura 2000 quede protegida".

En este sentido, actuaciones encaminadas al fomento del medio natural en espacios intersticiales de la Red parecen perfectamente justificadas y coherentes con la propia naturaleza y objetivos de la Directiva Hábitats en cuanto a fomento de la conectividad o la continuidad de espacios naturales, huyendo de rupturas territoriales que produjeran "efectos barreras" en las especies vegetales o animales. En definitiva, lo que se pretende con las medidas que se indican en el presente apartado es fomentar el carácter de "Red".

Asimismo, la Estrategia de la Comunidad Europea para la Conservación y Uso Sostenible de la Diversidad Biológica propone potenciar la conservación y el uso sostenible de la biodiversidad fuera de los espacios protegidos, prestando especial atención a los corredores ecológicos.

A su vez y como aspecto más importante, la Ley 42/2007, de 13 de diciembre, del Patrimonio Natural y de la Biodiversidad, que constituye la legislación básica estatal en lo que a protección y gestión de la biodiversidad se refiere, en su preámbulo señala claramente que los corredores ecológicos, deben ser incorporados en la planificación ambiental, otorgándoles un papel prioritario a las vías pecuarias y las áreas de montaña. Igualmente señala que "estos corredores ecológicos deben participar en el establecimiento de la red europea y comunitaria de corredores biológicos definidos por la Estrategia Paneuropea de Diversidad Ecológica y Paisajística y por la propia Estrategia Territorial Europea. En particular las Comunidades Autónomas podrán 
utilizar estos corredores ecológicos, o la definición de áreas de montaña, con el fin de mejorar la coherencia ecológica, la funcionalidad y la conectividad de la Red Natura 2000".

En este sentido, destacar dos artículos, el artículo 20 sobre corredores ecológicos y el artículo 46 sobre coherencia y conectividad de la red:

Artículo 20. Corredores ecológicos y Áreas de montaña.

"Las Administraciones Públicas preverán, en su planificación ambiental o en los Planes de Ordenación de los Recursos Naturales, mecanismos para lograr la conectividad ecológica del territorio, estableciendo o restableciendo corredores, en particular entre los espacios protegidos Red Natura 2000 y entre aquellos espacios naturales de singular relevancia para la biodiversidad. Para ello se otorgará un papel prioritario a los cursos fluviales, las vías pecuarias, las áreas de montaña y otros elementos del territorio, lineales y continuos, o que actúan como puntos de enlace, con independencia de que tengan la condición de espacios naturales protegidos.

Las Administraciones Públicas promoverán unas directrices de conservación de las áreas de montaña que atiendan, como mínimo, a los valores paisajísticos, hídricos y ambientales de las mismas”.

Artículo 46. Coherencia y conectividad de la Red.

"Con el fin de mejorar la coherencia ecológica y la conectividad de la Red Natura 2000, las Comunidades autónomas, en el marco de sus políticas medioambientales y de ordenación territorial, fomentarán la conservación de corredores ecológicos y la gestión de aquellos elementos del paisaje y áreas territoriales que resultan esenciales o revistan primordial importancia para la migración, la distribución geográfica y el intercambio genético entre poblaciones de especies de fauna y flora silvestre".

Este último artículo, señala claramente la necesidad de fomentar la conservación de aquellos espacios, estén o no bajo alguna figura de protección, que permita conectar distintos espacios territoriales de alto valor natural, para fomentar la migración, la distribución geográfica y el intercambio genético entre las especies, esencial para la adecuada gestión y conservación de los espacios y para asegurar la coherencia de la red, solicitada por la Directiva Hábitats.

Por tanto, parece justificado, tal y como queda desarrollado en el apartado 3, analizar acciones que permitan mejorar la conectividad de dos espacios de la Red Natura 2000 como son los Encinares de los ríos Adaja y Voltoya y Valles del Voltoya y el Zorita, mejorando la permeabilidad de los potenciales espacios territoriales que actúen como corredor ecológico y permitiendo la coherencia de la Red en este entorno. 


\section{IDENTIFICACIÓN Y JUSTIFICACIÓN DEL ÁMBITO TERRITORIAL SELECCIONADO}

Se ha pretendido tener en cuenta lo expuesto en las diferentes definiciones y en lo que refleja la citada Ley 42/2007, de 13 de diciembre, del Patrimonio Natural y de la Biodiversidad, escogiendo un área o más concretamente un elemento del medio natural que por su carácter mayoritariamente lineal sirva como elemento de conectividad entre diferentes espacios, y en este caso dos incluidos en la Red Natura 2000. Además del carácter lineal se ha buscado que el entorno circundante también disponga de elementos y unidades ambientales que permitan ampliar las potenciales propuestas de actuación que mejoren ecológica y socialmente este espacio. Pero junto a estos condicionantes, se ha querido que el espacio de análisis contase con características antrópicas que incidiesen directamente en él.

De esta manera, el territorio elegido se circunscribe al entorno del río Cardena, desde su nacimiento hasta su desembocadura en el río Voltoya. En este sentido, el río Cardeña tiene una importancia clave, dado que por un lado permite comunicar los LICs y ZEPAs Encinares de los ríos Adaja y Voltoya y Valles del Voltoya y el Zorita, caracterizados, entre otros valores naturales, por la presencia del águila imperial ibérica (Aquila adalberti). Por otro lado, junto a la existencia de otros elementos lineales próximos como vías pecuarias, el entorno del río Cardeña se encuentra presionado por distintos factores antrópicos.

No se debe olvidar, que las zonas ribereñas son de suma importancia en la prestación de una amplia gama de servicios ecológicos y sociales. Entre ellas, su papel en el mantenimiento de la conectividad del paisaje a través de corredores ecológicos para los animales y las plantas siendo de gran interés desde una perspectiva de conservación y gestión (Clerici and Vogt, 2013).

Para todo este entorno, se van a proponer, entre otras medidas, aquellas encaminadas principalmente a la recuperación ambiental del río Cardeña, mediante la retirada de residuos, biomasa, restauración de la vegetación de ribera, etc.,que permitan poder recuperar un entorno fluvial, afectado y presionado por las infraestructuras y los distintos usos colindantes. En este sentido, se propondrán otras que permitan mejorar sus características naturales y reducir potenciales barreras, de tal forma, que se mejore la conectividad entre los espacios Red Natura 2000, se potencie la biodiversidad de esa área, se mejore la permeabilidad ecosistémica, y se corrijan o minimicen los posibles elementos de fragmentación y/o degradación existentes.

En definitiva, se trata de actuar en un ámbito territorial que actualmente no está protegido (salvo $5,7 \mathrm{~km}$ de tramo de río) y que por tanto no está sujeto a una gestión concreta del medio natural, pero que alberga muchos de los Hábitats de Interés Comunitario que están presentes en los espacios que se quieren comunicar, por lo que existe una gran potencialidad para que en este caso, el río Cardeña y su entorno, actúe como conector ecológico. 
Mapa 1. Marco geográfico del ámbito de estudio.

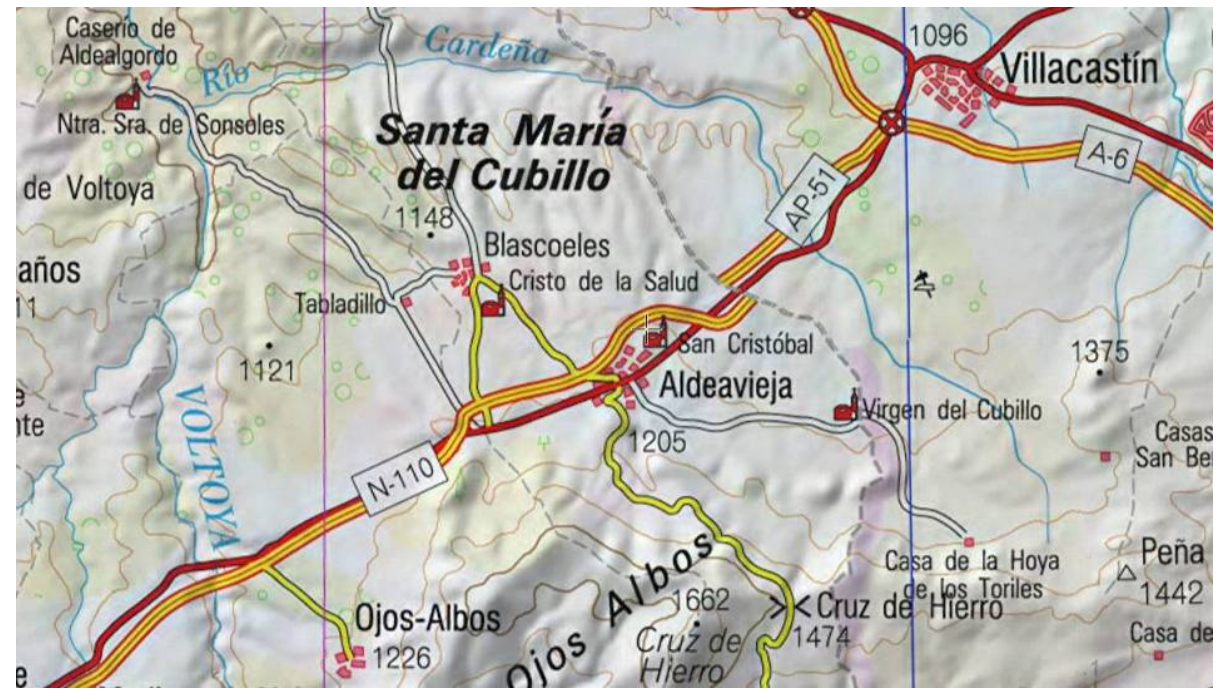

Fuente: SIG PAC.

Figura 1. Foto aérea del ámbito de estudio.

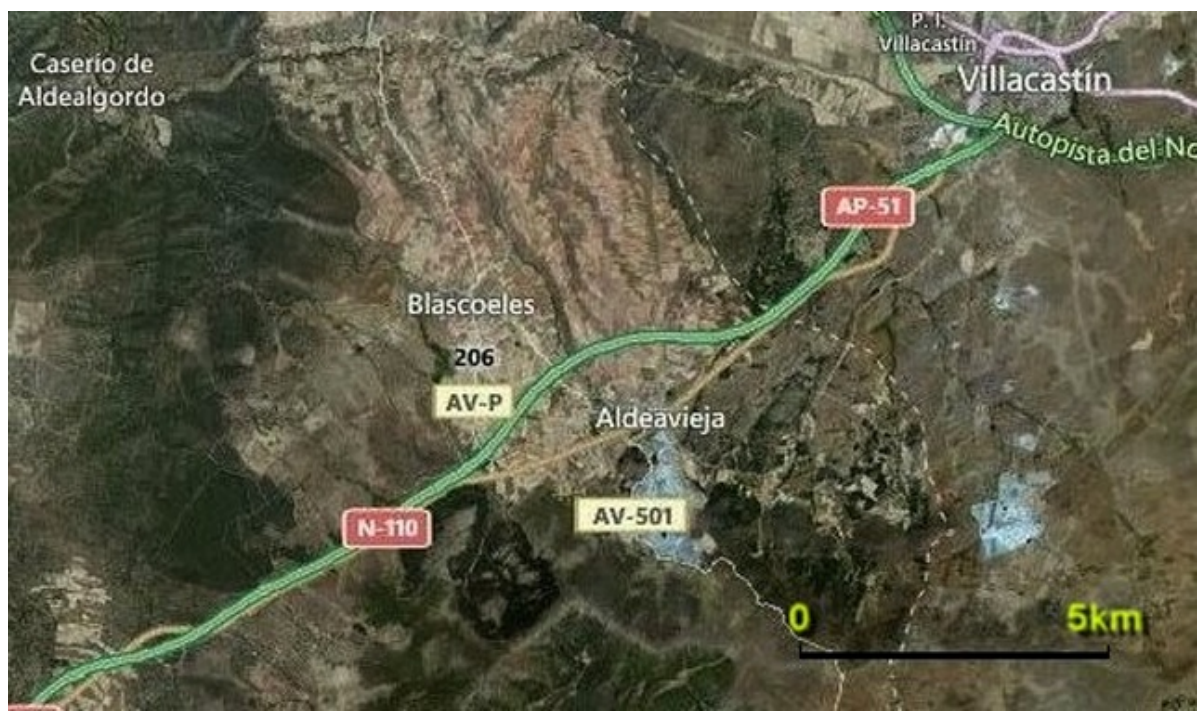

Fuente: Natura 2000 Viewer. Modificado. 


\section{DESCRIPCIÓN E INVENTARIO DEL ESPACIO DE ACTUACIÓN}

Para la descripción e inventario, se ha efectuado un trabajo de campo con el fin de identificar la vegetación y fauna presentes, los impactos antrópicos detectados y otros elementos lineales de interés para la conectividad como las vías pecuarias.

Los datos obtenidos en este estudio de campo se han completado con la información bibliográfica existente en las webs de la Consejería de Fomento y Medio Ambiente de la Junta Castilla y León y del Ministerio de Agricultura, Alimentación y Medio Ambiente (MAGRAMA), al igual que la presente en los diferentes Atlas Libros Rojos elaborados por el citado Ministerio. Así, al inventario de especies de fauna le acompaña una caracterización de las mismas en base a su grado de protección, fenología, y presencia y uso que las especies identificadas hacen de los distintos hábitats.

En lo que respecta al trabajo de campo se ha necesitado el empleo de una serie de material entre el que se incluye el siguiente:

- GPS con cartografía 1:25.000, con el fin de poder delimitar en los diferentes puntos de observación, la altura y sus coordenadas geográficas y UTM.

- Primáticos Opticrón 10x42, para el observación en detalle de las potenciales especies existentes y del arbolado presente. Dada la relativa amplitud del marco objeto de análisis, se declinó la posibilidad de emplear otro tipo de óptica de más aumentos como es el caso de telescopios.

- Cámara Panasonic Lumix DMC-FZ 72, con el objeto de poder realizar fotografía de detalle o de puntos alejados, pues dicha cámara emplea un zoom óptico de 60x (equivalente a teleobjetivo de $1200 \mathrm{~mm}$ ). Además, con el gran angular de $20 \mathrm{~mm}$ que dispone, se puede realizar fotografías panorámicas para visualizar con más claridad el entorno circundante.

- Mapa Topográfico Nacional de España a escala 1:25.000 del espacio en el que va a desarrollarse la actuación en formato papel y digital en el GPS. Se empleó con el fin de poder planificar las posibles rutas o lugares de tránsito, así como para delimitar los lugares de observación, con mejores panorámicas, etc.

- Fotografía aérea del marco territorial. Además de servir para lo indicado en relación al empleo del mapa topográfico, también se usó para delimitar los espacios naturales y antrópicos presentes, y la cobertura vegetal, así como el tamaño del arbolado existente con carácter previo al trabajo de campo.

\section{1. ÁMBITO TERRITORIAL}

El ámbito territorial del río Cardeña se enmarca entre el suroeste de la provincia de Segovia y el este de la provincia de Ávila en un espacio de transición entre las estribaciones occidentales de la Sierra de Guadarrama y las orientales de las denominadas Parameras de Ávila. Como poblaciones próximas se encuentran la segoviana de Villacastín y las abulenses de Aldeavieja, Blascoeles y Maello. 


\subsection{OROGRAFÍA E HIDROLOGÍA}

El espacio de estudio determinado por el río Cardeña muestra cerca de su nacimiento las mayores pendientes, que en todo caso no suponen un paisaje muy abrupto. Posteriormente, y relativamente encajado discurre hasta su desembocadura en el río Voltoya, una vez atravesadas las Laderas de las Cárcavas y de Cardeña, en donde forma pequeños meandros.

Figuras 2, 3, 4 y 5. Río Cardeña en diferentes tramos desde su nacimiento hasta las inmediaciones a su desembocadura.
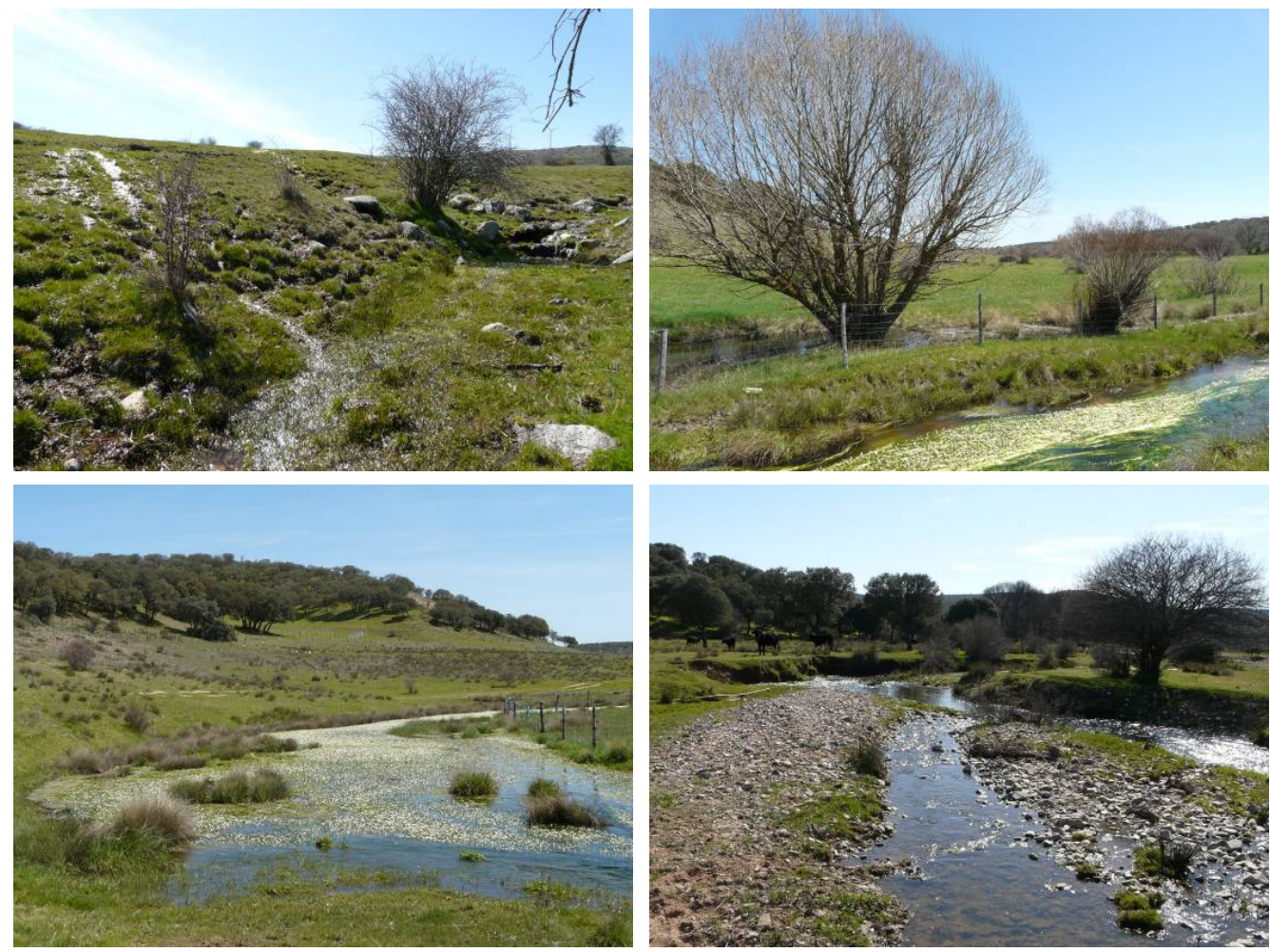

Fuente: Elaboración propia

Concretamente el río Cardeña, nace en las estribaciones orientales de la Sierra de Ojos Albos en las inmediaciones de Peña Morena (1.444 m), a unos $1355 \mathrm{~m}$ de altitud en el paraje denominado Fuente Taberna, mientras en su desembocadura la altura se acerca a los $970 \mathrm{~m}$, por lo que en su discurrir salva un desnivel de unos $385 \mathrm{~m}$ en sus aproximadamente $20 \mathrm{~km}$ de longitud. Su régimen es marcadamente pluvial, aunque en invierno puede tener un pequeño porcentaje nival. Recibe como afluentes o 
tributarios por la margen izquierda (sur) a los arroyos Valdelaloba, Galindo, del Marqués, del Cubillo, del Barranco, Valdelavilla, de las Rozas y Valdelacasa mientras los aportes por la margen derecha se derivan de la propia escorrentía y del arroyo Navalhuerto.

A pesar de la ausencia de embalses, el río Cardeña sufre, desafortunadamente, la invasión del Dominio Público Hidráulico, tanto de su Zona de Servidumbre, como de su Zona de Policía en algunos de sus tramos (curso medio-alto), fundamentalmente por la presencia de canteras de granito.

Además de la existencia de pozos, fuentes y abrevaderos, otro elemento hídrico de interés lo constituye la laguna de San Roque situada a poco más de un kilómetro del río y situada al norte de las Laderas de Cardeña.

\subsection{ESPACIOS NATURALES PROTEGIDOS (RED NATURA 2000)}

Los Lugares de Interés Comunitario (LICs) y las Zonas de Especial Protección para las Aves (ZEPAs) integran la Red Natura 2000 de la Unión Europea. Dichas zonas se fundamentan en la Directiva 92/43/CEE y en la Directiva 79/409 CEE, hoy reemplazada por la Directiva 2009/147/CE que contribuyen a garantizar la biodiversidad mediante la constitución de la Red Natura 2000.

Los LICs son espacios delimitados para garantizar el mantenimiento o, en su caso, el restablecimiento, en un estado de conservación favorable, de lo tipos de hábitats naturales de interés comunitario y de las especies de interés comunitario.

Las ZEPAs son espacios delimitados para el establecimiento de medidas de conservación especiales con el fin de asegurar la supervivencia y la reproducción de las especies de aves.

Junto al río Cardeña, se han declarado los siguientes LICs y ZEPAs:

- LIC: "Encinares de los ríos Adaja y Voltoya" (código UE: ES4110103). Superficie $23.007,32$ ha., ubicadas en un $98 \%$ en la provincia de Ávila y en un $2 \%$ en la de Segovia. Incluye un tramo aproximado de $1,7 \mathrm{~km}$ del río Cardeña en su desembocadura en el río Voltoya.

- LIC: "Valles del Voltoya y el Zorita" (código UE: ES4160111). Superficie $39.660,80$ ha., localizadas en un $97 \%$ en la provincia de Segovia y en un 3\% en la de Ávila. Incluye aproximadamente un tramo de unos $4 \mathrm{~km}$ del río Cardeña, al norte de la AP-51.

- ZEPA: "Encinares de los ríos Adaja y Voltoya" (código UE: ES0000190). Superficie 23.047,93 ha., ubicadas en un $98 \%$ en la provincia de Ávila y en un $2 \%$ en la de Segovia. Incluye al igual que en el LIC un tramo del río Cardeña en su desembocadura en el río Voltoya, pero de unos $200 \mathrm{~m}$ menos de longitud.

- ZEPA: "Valles del Voltoya y el Zorita" (código UE: ES0000188). Superficie 49.374,55 ha., localizadas en un $96 \%$ en la provincia de Segovia y en un $4 \%$ en la de Ávila. Incluye al igual que en el caso del LIC aproximadamente un tramo de unos $4 \mathrm{~km}$ del río Cardeña, al norte de la AP-51. 
Mapa 2. Distribución de la Red Natura 2000 junto al río Cardeña.

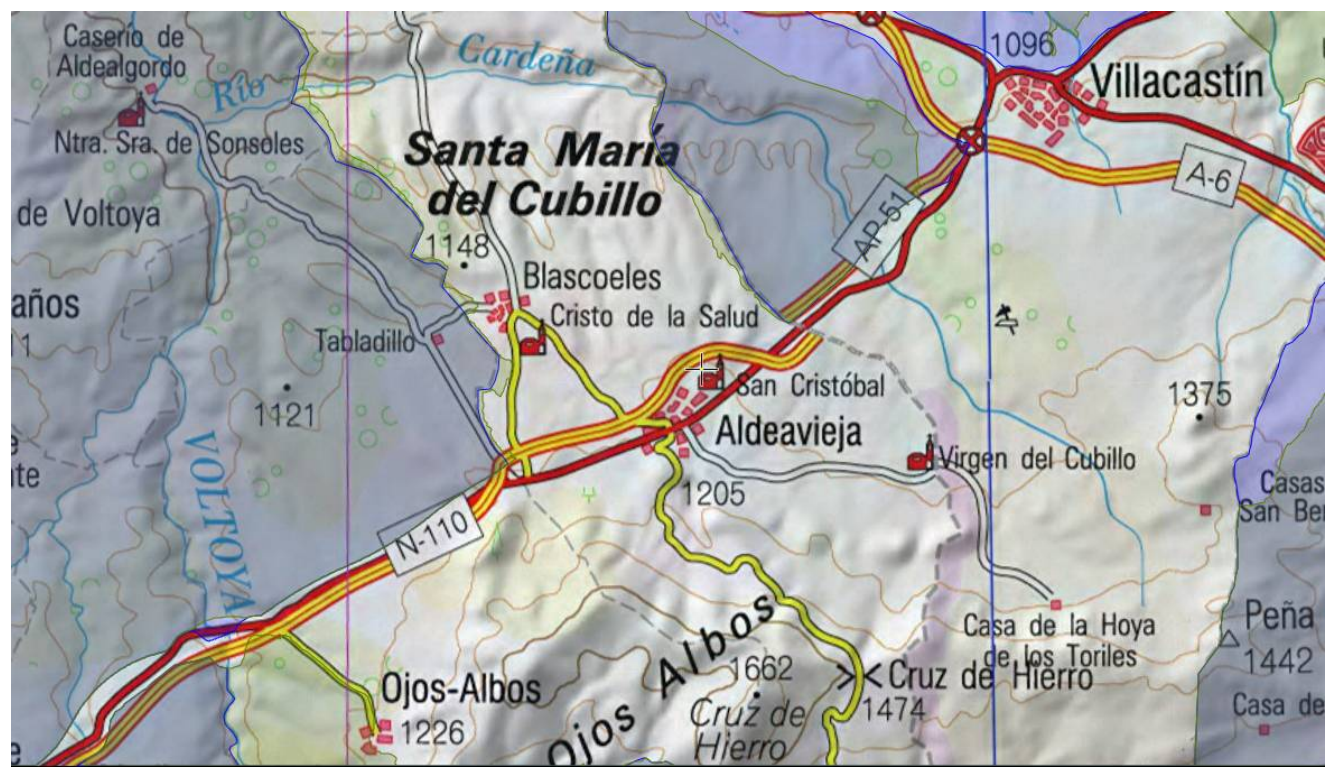

Fuente: SIGPAC.

\subsection{VEGETACIÓN Y POTENCIALES HÁBITATS DE INTERÉS COMUNITARIO}

En el ámbito de estudio y su entorno están representados distintos tipos de Hábitats de Interés Comunitario (HICs), incluidos en la Directiva 92/43/CEE del Consejo de 21 de mayo de 1992, relativa a la conservación de los hábitats naturales y de la fauna y flora silvestres, siendo los siguientes:

- Hábitat 91B01: Fresnedas termófilas de Fraxinus angustifolia. Algo escaso. Son especialmente comunes en el occidente ibérico mediterráneo, dada su preferencia por sustratos arenosos. Ocupan una posición intermedia entre los bosques de suelos secos (melojares, alcornocales, encinares, etc.) y las formaciones húmedas situadas hacia el borde del cauce (saucedas, alamedas o alisedas). El fresno puede aparecer también fuera de los cursos fluviales, en depresiones y vegas húmedas o zonas de surgencia. La fresneda de hoja

${ }^{1}$ Síntesis de la descripción de HICs realizada a partir del manual "Los Tipos de Hábitats de Interés Comunitario de España. Guía Básica”. 
estrecha es un bosque no muy cerrado y relativamente diverso. Suele llevar árboles de las bandas de vegetación adyacentes como Quercus pyrenaica, $Q$. faginea, Acer monspessulanum, etc. (propios de la vegetación no riparia), además de arbustos de medios húmedos, como Frangula alnus, Prunus spinosa, Rhamnus cathartica, Crataegus monogyna, etc. A veces se mezcla con otros árboles riparios, como Ulmus minor, Populus nigra, Salix salviifolia o S. atrocinerea. Entre las herbáceas destacan Arum maculatum, A. italicum, Elymus caninus, Glycyrrhiza glabra, Ranunculus ficaria, Iris foetidissima, etc. En bastantes áreas la estructura de las fresnedas ha sido alterada para formar dehesas o aparece de forma aislada.

- Hábitat 92A0: Bosques galería de Salix alba y Populus alba. Bastante representativo en la ribera del río Cardeña. Están presentes en los márgenes de los ríos en lugares con suelo al menos temporalmente encharcado o húmedo. En los cursos de agua, la vegetación forma bandas paralelas al cauce según el gradiente de humedad del suelo. Idealmente, en el borde del agua crecen saucedas arbustivas en las que se mezclan varias especies del género Salix (S. atrocinerea, S. triandra, S. purpurea), con Salix salvifolia. La segunda banda la forman alamedas y choperas, con especies de álamos (P. alba, P. nigra), sauces arbóreos (S. alba, S. fragilis), fresnos, etc. El sotobosque de estas formaciones lleva arbustos generalmente espinosos, sobre todo en los claros (Rubus, Rosa, Crataegus, Prunus, Sambucus, Cornus, etc.), herbáceas nemorales (Arum sp. pl., Urtica sp. pl., Ranunculus ficaria, Geum urbanum, etc.) y numerosas lianas (Humulus lupulus, Bryonia dioica, Cynanchum acutum, Vitis vinifera, Clematis sp. pl., etc.).

Figura 6. Habitat 92A0 de Bosques galería de Salix alba y Populus alba junto al río Cardeña.

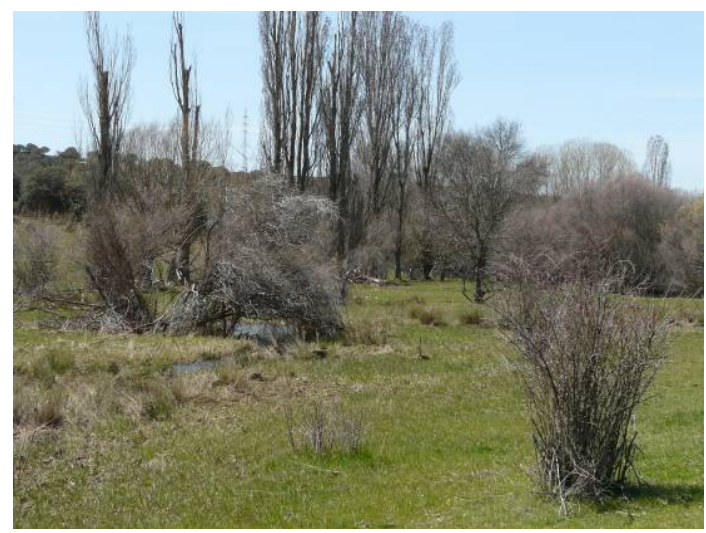

Fuente: Elaboración propia 
- Hábitat 9230: Robledales galaico portugueses con Quercus robur y Quercus pyrenaica (el único presente en este caso). Algo escaso, aunque perviven rodales en el ámbito territorial analizado principalmente en las cercanías a la $\mathrm{N}$ 110. Aparecen en sustratos ácidos con una pluviometría mínima de unos 500 $\mathrm{mm}$ y alturas entre los 500 y $1500 \mathrm{~m}$. Los melojares son bosques relativamente pobres; el estrato arbóreo es casi siempre monoespecífico, aunque puede acompañar al melojo algún arce (Acer opalus, A. monspessulanum), serbales (Sorbus aria, S. aucuparia, S. torminalis) o acebos (Ilex aquifolium). En el estrato arbustivo destacan Crataegus monogyna, especies de Rosa y Rubus, así como madreselvas (Lonicera peryclimenum), las tres primeras relativamente comunes en el entorno del río Cardeña. Las herbáceas aparecen dispersas, destacando Arenaria montana, Geum sylvaticum, Poa nemoralis, Melica uniflora, Brachypodium sylvaticum, Luzula forsterii, etc. En los bosques aclarados suele presentarse una orla de grandes leguminosas (Genista, Cytisus, Adenocarpus). El matorral de sustitución suele estar representado por las mismas leguminosas, además de por jaras (Cistus laurifolius, C. ladanifer, C. salviifolius, etc.).

Figura 7. Habitat 9230 con robledades de Quercus pyrenaica.

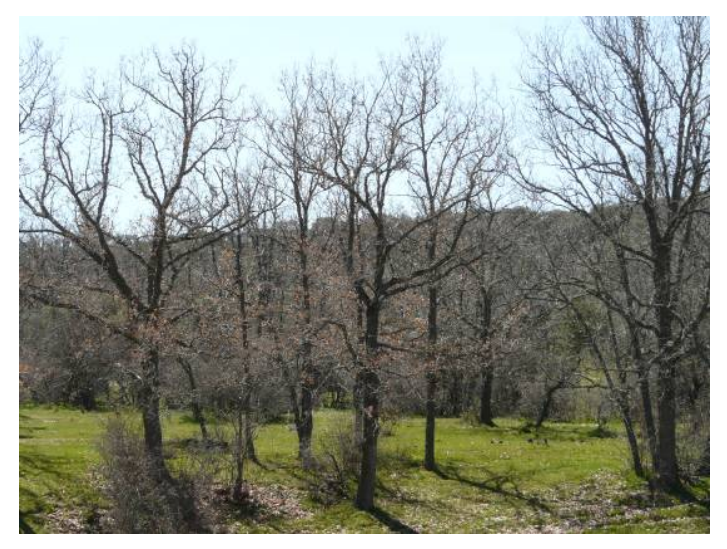

Fuente: Samantha Yablonovich Fernández.

- Hábitat 9340: Bosques de Quercus ilex y Quercus rotundifolia (la presente en el territorio de estudio). Relativamente representativo. Son los bosques dominantes de la Iberia mediterránea presentes en casi toda la Península. Los encinares continentales meseteños son los más pobres, con Juniperus, leguminosas (Retama, Cytisus, etc.), matorrales como de Cistus, Halimium, Lavandula, Thymus, y algunas hierbas forestales. Aparece de forma extensa en espacios próximos del río Cardeña, pero la mayor representatividad por su cercanía, se encuentra en la Laderas de las Cárcavas y al sur de las mismas, 
encontrándose también, aunque de manera empobrecida y en escasa extensión, en las Laderas de Cardeña.

Figura 8. Habitat 9340 con encinares.

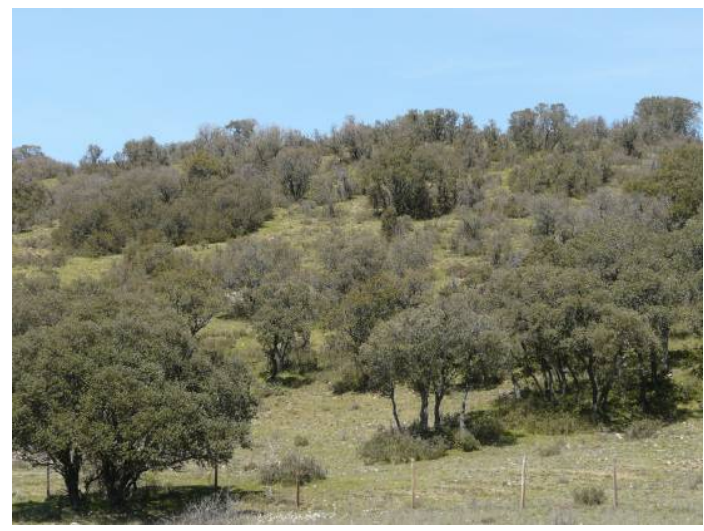

Fuente: Elaboración propia

- Hábitat 9540: Pinares mediterráneos de pinos mesogeanos endémicos. Escaso. Relativamente alejados del espacio de estudio (solo están presentes de manera puntual en alguna de las fincas privadas repartidas por el territorio o al sur del núcleo urbano de Aldeavieja y de la N-110). Están dominados por el pirófilo o inflamable por la resina Pinus pinaster con los condicionantes negativos que su presencia puede suponer en caso de incendio forestal y para su propagación, más aún al haber sido utilizado masivamente en algunas repoblaciones. Como especies acompañantes se encuentran algún Pinus sylvestris, Cistus ladanifer, C. laurifolius, Halimium viscosum, etc., o, en las áreas más occidentales, Cytisus scoparius, C. multiflorus, Cistus psilosepalus, Halimium alyssoides, Pteridium aquilinum, etc.

- Hábitat 6310: Dehesas perennifolias de Quercus spp. Algo escaso. Las dehesas, en este caso de encinas, constituyen un hábitat favorecido o creado por el hombre para uso múltiple (forestal, ganadero, agrícola o cinegético). En terrenos de relieves suaves y donde la agricultura es poco productiva, sobre sustratos preferentemente ácidos o neutros y con poca materia orgánica, se ha favorecido tradicionalmente este modo de uso del territorio. En aquellos terrenos en que se mantiene el matorral éste se compone de especies de Genista, Cytisus, Retama, Cistus o Halimium. Este hábitat aparece en menor medida que el 9340.

- Hábitat 5120: Formaciones montanas de Cytisus purgans. Muy escaso. A pesar de ser bastante abundante en otros espacios de mayor altitud dentro del Sistema Central, este matorral endémico además de situarse por encima del 
límite forestal, también entra en el sotobosque y en las orlas del robledal. Constituyen formaciones de porte bajo o almohadillado acompañando al piorno, el enebro de montaña (Juniperus communis subsp.alpina) que se mezclan en menor medida con erizones (Echinospartum), Adenocarpus o Genista, formando transiciones entre este hábitat y el 4090.

- Hábitat 5210: Matorrales arborescentes de Juniperus spp. Su representatividad y superficie es bastante escasa en el ámbito del río Cardeña. Se trata de formaciones de sustitución de bosques naturales de distinto tipo, actuando generalmente como etapa preforestal arbustiva, aunque a veces son comunidades permanentes en condiciones ambientales desfavorables (situaciones rocosas, secas, etc.), que impiden la evolución hacia el bosque. Ocupan todo tipo de suelos y viven desde el nivel del mar hasta el límite del bosque en las montañas, si bien las distintas especies de Juniperus ocupan diferente rango altitudinal. Juniperus communis es la especie más amplia, sustituyendo a distintas altitudes a diferentes formaciones forestales. Son formaciones abiertas en las que dominan grandes ejemplares arbustivos de Juniperus. Los espacios entre los individuos de Juniperus están ocupados por el matorral bajo de sustitución de los bosques predominantes en cada territorio o por pastizales. Dependiendo de la altitud y de la zona biogeográfica, son acompañados por formaciones de leguminosas y labiadas, coscojares, brezales, jarales y matorrales de cistáceas.

- Hábitat 5330: Matorrales termomediterráneos y pre-estépicos. Algo escaso. Son propios de climas algo cálidos, más bien secos, en todo tipo de sustratos. Actúan como etapa de sustitución de formaciones de mayor porte y presentan en general una amplia diversidad florística y estructural. En este hábitat suelen crecer matorrales de Retama sphaerocarpa, a veces $R$. monosperma, con especies de Genista o Cytisus, y tomillares ricos en labiadas endémicas (Thymus, Teucrium, Sideritis, Phlomis, Lavandula, etc.) que son las más comunes en el territorio analizado sobre todo en los lugares más soleados.

- Hábitat 3150: Lagos eutróficos naturales con vegetación Magnopotamion o Hydrocharition. Muy escaso. Se trata de lagos, lagunas, charcas y otros medios acuáticos estancados con aguas más o menos ricas en nutrientes, que permiten el desarrollo de comunidades vegetales acuáticas complejas en sustratos en este caso ácidos. Potencialmente puede localizarse en la laguna de san Roque y en otras pequeñas charcas existentes.

- Hábitat 3260: Ríos de pisos de planicie a montano con vegetación de Ranunculion fluitantis y de Callitricho-Batrachion. Representativo. Son típicos de porciones medias y bajas de los ríos de la mitad occidental ibérica, con caudal variable, como el Cardeña y afluentes, que contienen comunidades acuáticas sumergidas o de hojas flotantes. Como especies características aparecen entre otras: Ranunculus penicilatus, $R$. trichophyllus, R.peltatus, $R$. aquatilis, Myriophyllum verticillatum, M. alterniflorum, así como diferentes especies de Callitriche o briofitos acuáticos como Fontinalis antipyretica. 
- Hábitat 4090: Brezales oromediterráneos endémicos con aliaga. Muy escaso. Este tipo de hábitat, escaso en el espacio analizado, comprende los matorrales de altura de montaña, así como algunos matorrales de media montaña. Forman una banda arbustiva por encima de los niveles forestales o viven, como es el caso, en los claros y zonas degradadas del piso de los bosques. Las formaciones reconocidas de este tipo de hábitat presentan fisionomía diversa y una relativa amplia variación florística con especies como Cytisus scoparius, C. multiflorus, Adenocarpus hispanicus y otras endémicas de Echinospartum.

- Hábitat 6220 (prioritario): Zonas subestépicas de gramíneas y anuales del Thero- Brachypodietea. Algo escaso. Constituyen pastos xerófilos más o menos abiertos formados por diversas gramíneas y pequeñas plantas anuales, desarrollados sobre sustratos secos, ácidos en suelos generalmente poco desarrollados. Las comunidades de este hábitat prioritario presentan una gran diversidad. Se localizan en ambientes bien iluminados, ocupando los claros de matorrales y de pastos vivaces discontinuos, apareciendo también en repisas rocosas, donde forman el fondo de los pastos de plantas crasas. Se trata de comunidades de cobertura variable, compuestas por pequeñas plantas vivaces o anuales, a veces de desarrollo primaveral efímero. A pesar de su aspecto homogéneo, presentan gran riqueza y variabilidad florísticas, con abundancia de endemismos del Mediterráneo occidental. Entre los géneros más representativos están Arenaria, Campanula, Linaria, Silene, Euphorbia, Rumex, Plantago, Bupleurum, Brachypodium, Bromus, Stipa, Poa, Trifolium, Tuberalia, Vulpia, Coronilla, etc.

- Hábitat 6420: Prados húmedos mediterráneos de hierbas altas del MolinionHoloschoenion. Escaso. Forman comunidades vegetales que crecen sobre cualquier tipo de sustrato, pero con preferencia por suelos ricos en nutrientes, y que necesitan la presencia de agua subterránea cercana a la superficie. En la época veraniega suele producirse un descenso notable de la capa de agua, pero no tanto como para resultar inaccesible al sistema radicular de los juncos y otras herbáceas. Son muy comunes en hondonadas que acumulan agua en época de lluvias, así como en riberas de ríos y arroyos, donde acompañan a distintas comunidades riparias (choperas, saucedas, etc.) como es el caso. Dan lugar a praderas densas, verdes todo el año, en las que destacan diversos juncos formando un estrato superior de altura media, a menudo discontinuo. Aunque su aspecto es homogéneo, presentan gran variabilidad y diversidad florística. Las familias dominantes son las ciperáceas y juncáceas, con Scirpoides holoschoenus (= Scirpus holoschoenus), Cyperus longus, Carex mairii, J. maritimus, J. acutus, etc. Son frecuentes gramíneas como Briza minor, Melica ciliata, Cynodon dactylon, especies de Festuca, Agrostis, Poa, etc., además de un amplio cortejo de taxones como Cirsium monspessulanun, Tetragonolobus maritimus, Lysimachia ephemerum, Prunella vulgaris, Senecio doria, o especies de Orchis, Pulicaria, Hypericum, Euphorbia, Linum, Ranunculus, Trifolium, Mentha, Galium, etc. 
- Hábitat 6430: Megaforbios eutrofos higrófilos de las orlas de llanura y de los pisos montano y alpino. Muy escaso. Estas comunidades con aspecto diverso se encuentran dominadas por herbáceas de gran talla o lianas, propias de suelos con cierta humedad, ricos en materia orgánica y con un grado de luminosidad variable, pudiendo aparecer en linderos de bosque. Entre las potenciales especies se pueden encontrar Myrrhoides nodosa, Alliaria petiolata, Chaerophyllum temulentum, Lapsana communis, y sobre todo la Urtica dioica, todas ellas presentes en situaciones umbrosas de suelos forestales.

- Hábitat 6510: Prados pobres de siega de baja altitud (Alopecurus pratensis, Sanguisorba officinalis). Escaso. Está constituidos por prados de interés ganadero fertilizados, sometidos a una o dos siegas al año y a veces pastoreados directamente. Son típicos de zonas montanas de la mitad norte peninsular, desarrollándose sobre suelos profundos en donde la diversidad específica de especies les confiere una vistosa floración.

Además de la vegetación incluida en estos HICs, en el ámbito territorial, especialmente al norte de las Laderas de cardeña y al sur de las mismas a pesar de la ondulación, aparecen otros usos del suelo principalmente dominados por áreas cultivadas esencialmente de cereal (incluyendo los que alternan con barbecho) o regadío y pequeños huertos de diferentes hortalizas.

Tabla 1. Listado (según Código UE) de HICs existentes en los espacios Red Natura 2000 presentes en las proximidades del río Cardeña.

\begin{tabular}{|c|c|c|c|}
\hline $\begin{array}{c}\text { HICs en la ZEPA } \\
\text { ES0000188 “Valles del } \\
\text { Voltoya y el Zorita” }\end{array}$ & $\begin{array}{c}\text { HICs en el LIC } \\
\text { ES4160111 “Valles del } \\
\text { Voltoya y el Zorita” }\end{array}$ & $\begin{array}{c}\text { HICs en la ZEPA } \\
\text { ES0000190 “Encinares } \\
\text { de los ríos Adaja y } \\
\text { Voltoya” }\end{array}$ & $\begin{array}{c}\text { HICs en el LIC } \\
\text { ES4110103 “Encinares } \\
\text { de los ríos Adaja y } \\
\text { Voltoya” }\end{array}$ \\
\hline 3150 & 3150 & 3260 & 3260 \\
\hline 3260 & 3260 & 4090 & 5090 \\
\hline 4090 & 4090 & 5210 & 5330 \\
\hline 5120 & 5120 & 5330 & 6220 \\
\hline 5210 & 5210 & 6220 & 6310 \\
\hline 5330 & 5330 & 6310 & 6420 \\
\hline 6220 & 6220 & 6420 & 9430 \\
\hline 6310 & 6310 & 6430 & $92 \mathrm{~B} 0$ \\
\hline 6420 & 6420 & $91 \mathrm{~B} 0$ & 9340 \\
\hline 6430 & 6430 & $92 \mathrm{~A} 0$ & 9540 \\
\hline 6510 & 6510 & 9340 & \\
\hline $91 \mathrm{~B} 0$ & $91 \mathrm{~B} 0$ & 9540 & \\
\hline 9230 & 9230 & & \\
\hline $92 \mathrm{~A} 0$ & $92 \mathrm{~A} 0$ & & \\
\hline 9340 & 9340 & & \\
\hline 9540 & 9540 & & \\
\hline \multicolumn{3}{|l}{}
\end{tabular}

Fuente: Magrama y Junta de Castilla y León. Modificado. 


\subsection{FAUNA}

Destaca por su variedad y por la presencia de un elevado número de especies protegidas. Para su estudio, se ha realizado un inventario, de las especies de vertebrados presentes más representativas acompañado de una caracterización de las mismas en base a su grado de protección y potencial hábitat del que hacen uso a partir básicamente de los HICs descritos en el apartado 4.4.

Dentro del grado de protección se ha tenido en cuenta la caracterización efectuada en el Real Decreto 139/2011, de 4 de febrero, para el desarrollo del Listado de Especies Silvestres en Régimen de Protección Especial y del Catálogo Español de Especies Amenazadas, así como por la Lista Roja de la Unión Internacional para la Conservación de la Naturaleza (UICN) e incluida en el Libro Rojo de los diferentes vertebrados españoles. En el caso del R.D 139/2011 en el artículo 5 se cataloga a las especies en las siguientes categorías, a las que hay que sumar aquellas presentes en el Listado de Especies Silvestres en Régimen de Protección Especial y en el Catálogo $(\mathrm{P})$ :

- En peligro de extinción (E): especie, subespecie o población de una especie cuya supervivencia es poco probable si los factores causales de su actual situación siguen actuando.

- Vulnerable (V): especie, subespecie o población de una especie que corre el riesgo de pasar a la categoría anterior en un futuro inmediato si los factores adversos que actúan sobre ella no son corregidos.

Mientras, las categorías de protección válidas a nivel internacional por la UICN (2001) aplicables a la realidad española serán las siguientes:

- En Peligro Crítico (CR): La especie o subespecie se enfrenta a un riesgo extremadamente alto de extinción en estado silvestre en un futuro inmediato.

- En Peligro (EN): No en peligro crítico, pero enfrentado a un riesgo muy alto de extinción en estado silvestre en un futuro cercano.

- Vulnerable (VU): Alto riesgo de extinción en estado silvestre a medio plazo.

- Casi Amenazado (NT): Aunque no satisface los criterios de Vulnerable, está próximo a hacerlo de forma inminente o en un futuro.

- Datos Insuficientes (DD): La información disponible no es adecuada para hacer una evaluación del grado de amenaza.

- Preocupación Menor (LC): No cumple ninguno de los criterios de las categorías anteriores.

- Taxones No Evaluados (NE): Taxón no evaluado en relación a los criterios objetivos proporcionados por UICN (1994). 
Tabla 2. Listado de especies faunísticas existentes en el entorno del río Cardeña.

\begin{tabular}{|c|c|c|c|c|c|}
\hline Nombre Común & Nombre Científico & $\begin{array}{c}\text { Hábitats en que están } \\
\text { presentes } \\
\text { (Código UE) }\end{array}$ & Catálogo Nacional & $\begin{array}{c}\text { Categoría de } \\
\text { protección UICN }\end{array}$ & Fenología \\
\hline \multicolumn{6}{|c|}{ AVES } \\
\hline Cigüeña negra & Ciconia nigra & 6310,9340 y 9540 & $\mathrm{~V}$ & $\mathrm{VU}$ & $\mathrm{R}$ \\
\hline Alimoche & $\begin{array}{c}\text { Neophron } \\
\text { percnopterus }\end{array}$ & Roquedos & V & EN & $\mathrm{P}$ \\
\hline Aguilucho cenizo & Circus pygargus & Cultivos de secano & $\mathrm{V}$ & VU & $\mathrm{R}$ \\
\hline Águila imperial & Aquila adalberti & 6310 y 9340 & E & $\mathrm{EN}$ & $\mathrm{S}$ \\
\hline Cernícalo vulgar & Falco tinunculus & $\begin{array}{l}6310,9340,91 \mathrm{~B} 0, \\
9230,92 \mathrm{~A} 0 \text { y } 9540 \\
\end{array}$ & $P$ & VU & S \\
\hline $\begin{array}{c}\text { Cernícalo } \\
\text { primilla }\end{array}$ & Falco naumanni & Edificios abandonados & $\mathrm{P}$ & VU & $\mathrm{R}$ \\
\hline Espátula común & Platalea leucorodia & $92 \mathrm{~A} 0,3150$ y 3260 & $\mathrm{P}$ & $\mathrm{VU}$ & $\mathrm{P}$ \\
\hline Milano real & Milvus milvus & $\begin{array}{l}9340,6310,92 \mathrm{~A} 0, \\
91 \mathrm{~B} 0,9230 \text { y } 9540\end{array}$ & $\mathrm{E}$ & $\mathrm{EN}$ & $\mathrm{S}$ \\
\hline Águila pescadora & Pandion haliaetus & 3150 y 3260 & $\mathrm{P}$ & $\mathrm{CR}$ & $\mathrm{P}$ \\
\hline $\begin{array}{c}\text { Chorlito } \\
\text { carambolo }\end{array}$ & $\begin{array}{l}\text { Charadrius } \\
\text { morinellus }\end{array}$ & 6420 & V & EN & $P$ \\
\hline Fumarel común & Chlidonias niger & 3150 y 6420 & E & EN & $P$ \\
\hline Avetoro común & Botaurus stellaris & 3150 & E & $\mathrm{CR}$ & $\mathrm{P}$ \\
\hline Sisón & Tetrax tetrax & 6220,6420 y cultivos & $\mathrm{V}$ & VU & $\mathrm{R}$ \\
\hline Ganga ortega & Pterocles orientalis & Barbechos y 6510 & $\mathrm{~V}$ & $\mathrm{VU}$ & $\mathrm{S}$ \\
\hline Gavilán & Accipiter nisus & 9230 y 9540 & $P$ & & $\mathrm{~S}$ \\
\hline Azor común & Accipiter gentilis & 9230 y 9540 & $\mathrm{P}$ & $\mathrm{VU}$ & $\mathrm{S}$ \\
\hline \multicolumn{6}{|c|}{ MAMÍFEROS } \\
\hline $\begin{array}{c}\begin{array}{c}\text { Topillo de } \\
\text { Cabrera }\end{array} \\
\end{array}$ & Microtus cabrerae & 6220,6420 y 6510 & $P$ & VU & $\mathrm{S}$ \\
\hline Gato montés & $\begin{array}{c}\text { Felis sylvestris } \\
\text { tartesia }\end{array}$ & $\begin{array}{c}91 \mathrm{~B} 0,9230,9340 \mathrm{y} \\
9540\end{array}$ & $P$ & VU & $\mathrm{S}$ \\
\hline Rata de agua & Arvicola sapidus & $92 \mathrm{~A} 0,3150$ y 3260 & & VU & $\mathrm{S}$ \\
\hline $\begin{array}{l}\text { Murciélago } \\
\text { grande de } \\
\text { herradura }\end{array}$ & $\begin{array}{l}\text { Rinolophus } \\
\text { ferrumequinum }\end{array}$ & $\begin{array}{c}\text { Cuevas, } 91 \mathrm{~B} 0,9230 \\
9340,9540 \text { y } 6310\end{array}$ & V & NT & $\mathrm{S}$ \\
\hline $\begin{array}{c}\text { Murciélago } \\
\text { ratonero grande }\end{array}$ & Myotis myotis & $\begin{array}{c}\text { Cavidades, } 9230,9340 \\
\text { y } 9540 \\
\end{array}$ & V & VU & S \\
\hline $\begin{array}{c}\text { Murciélago } \\
\text { ratonero mediano }\end{array}$ & Myotis blythii & $\begin{array}{c}\text { Cuevas, } 6220,6420 \mathrm{y} \\
6510\end{array}$ & $\mathrm{~V}$ & $\mathrm{VU}$ & S \\
\hline $\begin{array}{c}\text { Murciélago de } \\
\text { cueva }\end{array}$ & $\begin{array}{l}\text { Miniopterus } \\
\text { schreibersi }\end{array}$ & Cuevas & V & VU & $\mathrm{S}$ \\
\hline $\begin{array}{c}\text { Murciélago } \\
\text { mediterráneo de } \\
\text { herradura }\end{array}$ & Rhinolophus euryale & $\begin{array}{c}\text { Cuevas, } 6310,9340 \mathrm{y} \\
9230\end{array}$ & V & VU & S \\
\hline Nóctulo grande & Nyctalus lasiopterus & 9230 y 9540 & $\mathrm{~V}$ & $\mathrm{VU}$ & $\mathrm{S}$ \\
\hline $\begin{array}{c}\text { Murciélago } \\
\text { hortelano }\end{array}$ & Eptesicus serotinus & Variados & V & & $\mathrm{s}$ \\
\hline \multicolumn{6}{|c|}{$\begin{array}{l}\text { ANFIBIOS } \\
\end{array}$} \\
\hline Sapo común & Bufo bufo & $\begin{array}{c}91 \mathrm{~B} 0,92 \mathrm{~A} 0,3150 \mathrm{y} \\
3260\end{array}$ & & $\mathrm{LC} / \mathrm{VU}$ & $\mathrm{S}$ \\
\hline $\begin{array}{l}\text { Salamandra } \\
\text { común }\end{array}$ & $\begin{array}{c}\text { Salamandra } \\
\text { salamandra bejarae }\end{array}$ & $\begin{array}{c}91 \mathrm{~B} 0,92 \mathrm{~A} 0,3150 \mathrm{y} \\
3260\end{array}$ & $P$ & VU & S \\
\hline Rana patilarga & Rana iberica & $\begin{array}{c}91 \mathrm{~B} 0,92 \mathrm{~A} 0,3150 \mathrm{y} \\
3260\end{array}$ & $P$ & VU & $\mathrm{S}$ \\
\hline \multicolumn{6}{|c|}{ REPTILES } \\
\hline Galápago leproso & Mauremys leprosa & $\begin{array}{c}91 \mathrm{~B} 0,92 \mathrm{~A} 0,3150 \mathrm{y} \\
3260\end{array}$ & $P$ & VU & $\mathrm{S}$ \\
\hline \multicolumn{6}{|c|}{ PECES } \\
\hline Bermejuela & $\begin{array}{c}\text { Chondrostoma } \\
\text { arcasii }\end{array}$ & 3260 y i $3150 ?$ & $P$ & VU & $\mathrm{S}$ \\
\hline
\end{tabular}

Fuente: Magrama y Junta de Castilla y León. Modificado. 
A partir de las categorías de protección indicadas en la normativa estatal y en la UICN, y considerando los HICs definidos, así como la fenología de la especie ya sea sedentaria (S) o migratoria en este caso reproductora (R), invernante (I) o en paso (P), a continuación en la siguiente tabla se señalan las especies de vertebrados más representativas existentes (categorías en peligro de extinción, en peligro crítico, en peligro, y vulnerable) en el ámbito de estudio en función de lo reflejado en las fichas de los LICs y ZEPAs existentes, los Atlas y Libros Rojos y en las observaciones de campo efectuadas.

\subsection{VÍAS PECUARIAS}

Se entiende por vía pecuaria como el camino, ruta o itinerario por donde discurre o ha venido discurriendo tradicionalmente el tránsito ganadero. El conjunto de vías pecuarias españolas constituye un patrimonio histórico único en Europa y en el mundo.

Las vías pecuarias constituyen testimonios físicos de un modo de utilización y aprovechamiento del territorio y de un desarrollo económico tradicional en la región. Actualmente, junto a la función prioritaria del tránsito de ganado, que permite el aprovechamiento de recursos pastables infrautilizados, se desempeñan otras funciones importantes como las patrimoniales, el papel en la diversidad paisajística, la contribución en la mejora de la gestión y conservación de los espacios naturales, el fomento de la biodiversidad al posibilitar el intercambio genético en las especies vegetales y animales, el incrementar el contacto social con la naturaleza y el permitir el desarrollo de actividades de tiempo libre compatibles con el respeto de la conservación del medio natural.

A nivel nacional, la ley 3/1995 de 23 de Marzo, regula los aspectos básicos de la protección de las vías pecuarias, considerándolas como bienes de dominio público, lo que significa que son inalienables, imprescriptibles e inembargables. En esta normativa en su artículo 4.1 se clasifica a las vías pecuarias en las siguientes categorías:

- Cañadas: Son aquellas vías cuya anchura máxima no sobrepase los $75 \mathrm{~m}$.

- Cordeles: Son aquellas vías cuya anchura máxima no sobrepase los $37,5 \mathrm{~m}$.

- Veredas: Son aquellas vías cuya anchura máxima no sobrepase los $20 \mathrm{~m}$.

Como se indica en la Ley 42/2007, de 13 de diciembre, del Patrimonio Natural y de la Biodiversidad, las vías pecuarias tienen un papel prioritario para la conectividad ecológica, pudiendo funcionar como corredores ecológicos y colaborar en la mejora de la coherencia ecológica, la funcionalidad y la conectividad de la Red Natura 2000.

Es por esta razón, que la presencia de vías pecuarias en el ámbito de actuación, aumenta la permeabilidad del territorio y la posibilidad de realizar actuaciones en las mismas, por lo que mejora sus condiciones naturales para potenciar su papel como corredor ecológico.

Partiendo de estas consideraciones en el ámbito territorial del río Cardeña se encuentran las siguientes vías pecuarias: 
- Cañada Real Leonesa Oriental. Es una de la principales cañadas existentes a nivel nacional, circunscribiéndose en el territorio de estudio a las inmediaciones del nacimiento del río Cardeña hasta aproximadamente el punto en que es atravesada por una línea eléctrica de alta tensión de $132 \mathrm{kV}$. Su trazado rectilíneo de sur a norte discurre en los dos primeros kilómetros en paralelo al río Cardeña, para posteriormente tras $4 \mathrm{~km}$ dirigirse hasta el sur del núcleo urbano de Villacastín, en donde, una vez trascurridos otros $4 \mathrm{~km}$ en dirección noreste, se llega hasta la línea eléctrica citada anteriormente, para luego con orientación norte, atravesar la AP-6 abandonado ya el espacio de estudio. Puede decirse, por tanto, que su longitud aproximada en ámbito de actuación asciende a unos $10 \mathrm{~km}$. En su parte norte se integra en el LIC y ZEPA "Valles del Voltoya y del Zorita".

Figura 9. Cañada Real Leonesa Oriental.

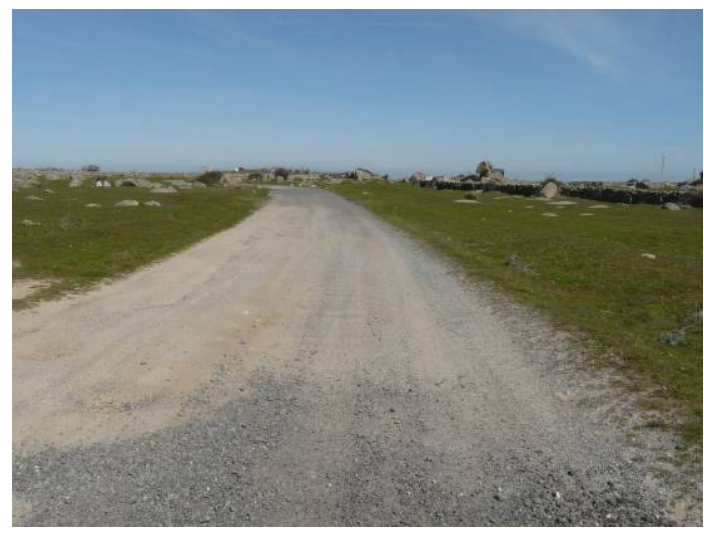

Fuente: Samantha Yablonovich Fernández.

- Cañada de Valdeherreros. Parte desde Blascoeles en dirección NW hasta el río Cardeña a $1,5 \mathrm{~km}$ de su desembocadura en el Voltoya. Linda con el LIC y ZEPA "Encinares de los ríos Adaja y Voltoya".

- Colada de la Raya de Navas. Parte desde el sur de la AP-6 a la altura de la urbanización Coto de San Isidro para posteriormente en dirección suroeste unirse con la Cañada Real Leonesa Oriental tras atravesar la ladera del Alto de los Cebollos. Su longitud es de poco más de $4 \mathrm{~km}$. En su origen se integra en la ZEPA "Valles del Voltoya y del Zorita", lindando con el LIC del mismo nombre.

- Vereda de Cañada Verde. Tiene su origen junto a la Colada de la Raya de Navas discurriendo a continuación por el sur del núcleo urbano de Villacastín 
para a continuación transitar en paralelo junto a la N-110 hasta el límite con la provincia de Ávila. Su longitud supera ligeramente los $9 \mathrm{~km}$. En su origen se integra en la ZEPA "Valles del Voltoya y del Zorita", lindando con el LIC del mismo nombre.

\subsection{ELEMENTOS ANTRÓPICOS Y/O POSIBLES AFECCIONES}

A pesar de encontrarse el espacio de estudio en un marco claramente rural, esto no le exime de la existencia de un considerable número de elementos antrópicos y/o afecciones que dificultan la conectividad entre diferentes territorios y empeoran su calidad ecológica y paisajística. Entre ellos se encuentran los siguientes:

- Canteras. Están ubicadas en el curso alto del río, siempre al sur de la N-110. En el caso de tres de ellas están situadas incomprensiblemente en el Dominio Público Hidraúlico del río Cardeña, incluso la situada más al sur en la propia Zona de Servidumbre. Además de estas tres canteras, hay otras cinco ubicadas a distancias que oscilan entre $\operatorname{los} 150 \mathrm{~m}$ y $1 \mathrm{~km}$ del río Cardeña, existiendo otra más alejada a unos $3,5 \mathrm{~km}$ que se encuentra situada al sur de la localidad de Aldeavieja junto a la carretera que llega hasta el Puerto de la Cruz de Hierro.

- Parques eólicos. Están presentes a lo largo de toda la línea de cumbres de la Sierra de Ojos Albos, habiendo transformado negativamente el paisaje de estas montañas. El aerogenerador más próximo se encuentra a unos $650 \mathrm{~m}$ al suroeste del nacimiento del río Cardeña.

- Infraestructuras del transporte. Además de la carretera provincial que une las localidades de Blascoéles y Maello y que atraviesa el río Cardeña, éste también es cruzado por otras vías de comunicación de mayor importancia como son la AP-51 y la N-110. Mientras, al este del río Cardeña a más de 1 $\mathrm{km}$ se encuentran la AP-6 y la N-VI.

- Tendidos eléctricos. Aunque existen varios por el territorio, el más destacado es uno de $132 \mathrm{kV}$ que parte desde Ávila capital y atraviesa tanto los LICs y ZEPAs "Encinares de los ríos Adaja y Voltoya y Valles del Voltoya y del Zorita" como el propio río Cardeña entre las Laderas de Cardeña y de las Cárcavas. Llega hasta la localidad de Lastras de Pozo (Segovia) si bien bastante antes cruza la AP-6, la N-VI, y a la altura de estas infraestructuras del transporte en paralelo a las mismas, otro tendido eléctrico de mayor tensión en este caso de $380 \mathrm{kV}$ pasa por el norte del núcleo urbano de Villacastín.

- Gaseoducto. Une Ávila y Segovia y discurre en paralelo a la N-110.

- Núcleos urbanos. Destaca Villacastín en Segovia con nuevas áreas de urbanización hacia el noroeste para fines empresariales e industriales. Otros pequeños espacios urbanizados del entorno los constituyen Aldeavieja, Blascoeles y Maello en Ávila.

- Actividades agrícolas. Su presencia ha supuesto la deforestación de algunas áreas. 
- Vallado del cauce y riberas del río Cardeña invadiendo su Dominio Público Hidráulico en algunos puntos.

- Vertidos incontrolados de residuos. En cuanto a los residuos sólidos urbanos (RSU) su presencia es bastante escasa apareciendo de manera puntual en las inmediaciones a las infraestructuras del transporte como la AP-6 y la AP-51. Además, aparecen restos de podas de encina en la parte más septentrional de la Cañada de Valdeherreros en el punto más cercano al río Cardeña.

- Cuartel de caza intensiva (figura recogida en el artículo 56 de la Ley 4/1996, de 12 de julio, de Caza, de Castilla y León) dentro del LIC y ZEPA "Encinares de los ríos Adaja y Voltoya", en concreto en los encinares de la Dehesa de Tabladillo, al sur de la desembocadura del río Cardeña lindando o incluso dentro del Dominio Público Hidraúlico (Zona de Policía).

Figuras 10, 11, 12, 13, 14, 15 y 16. Ejemplos de algunos de los elementos antrópicos en el ámbito del río Cardeña (canteras, gaseoducto, apoyos con riesgo de electrocución para las aves e invasión del Dominio Público Hidráulico).

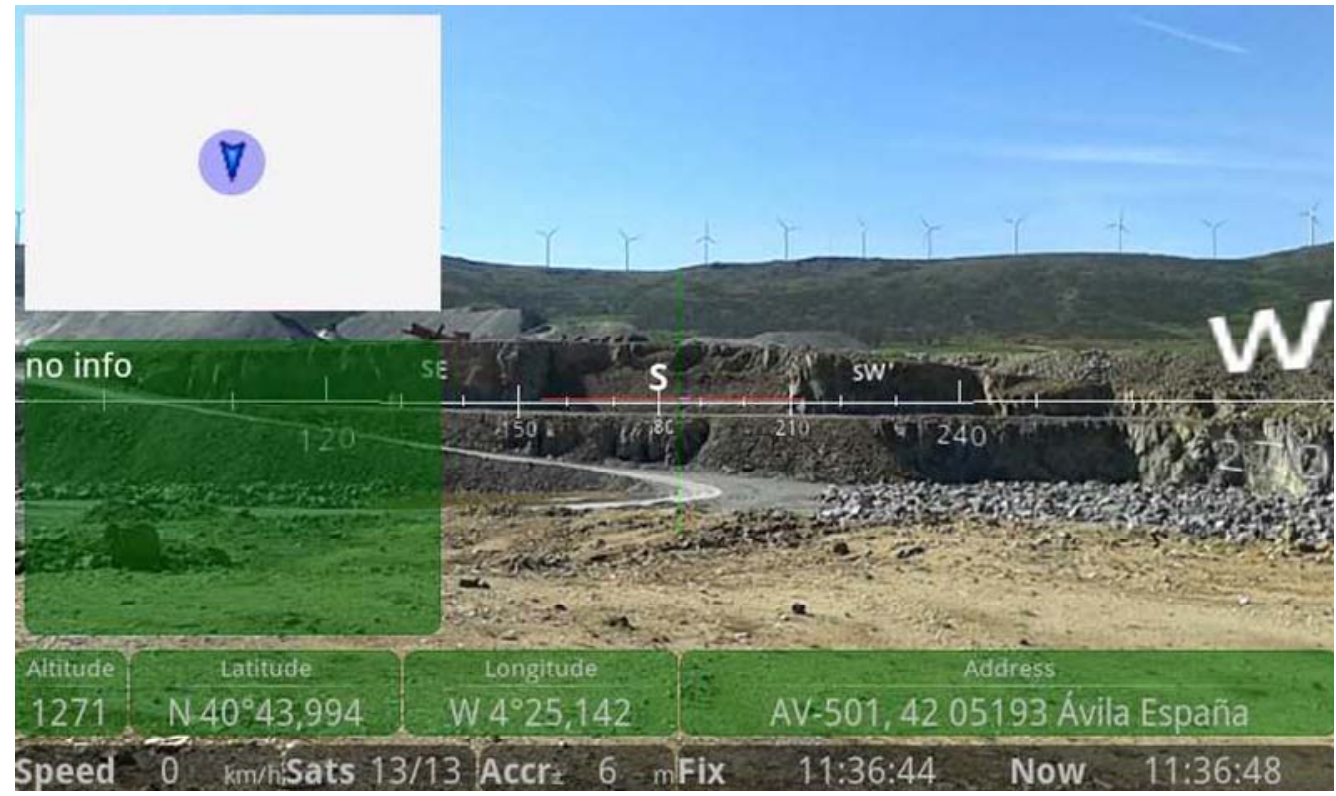



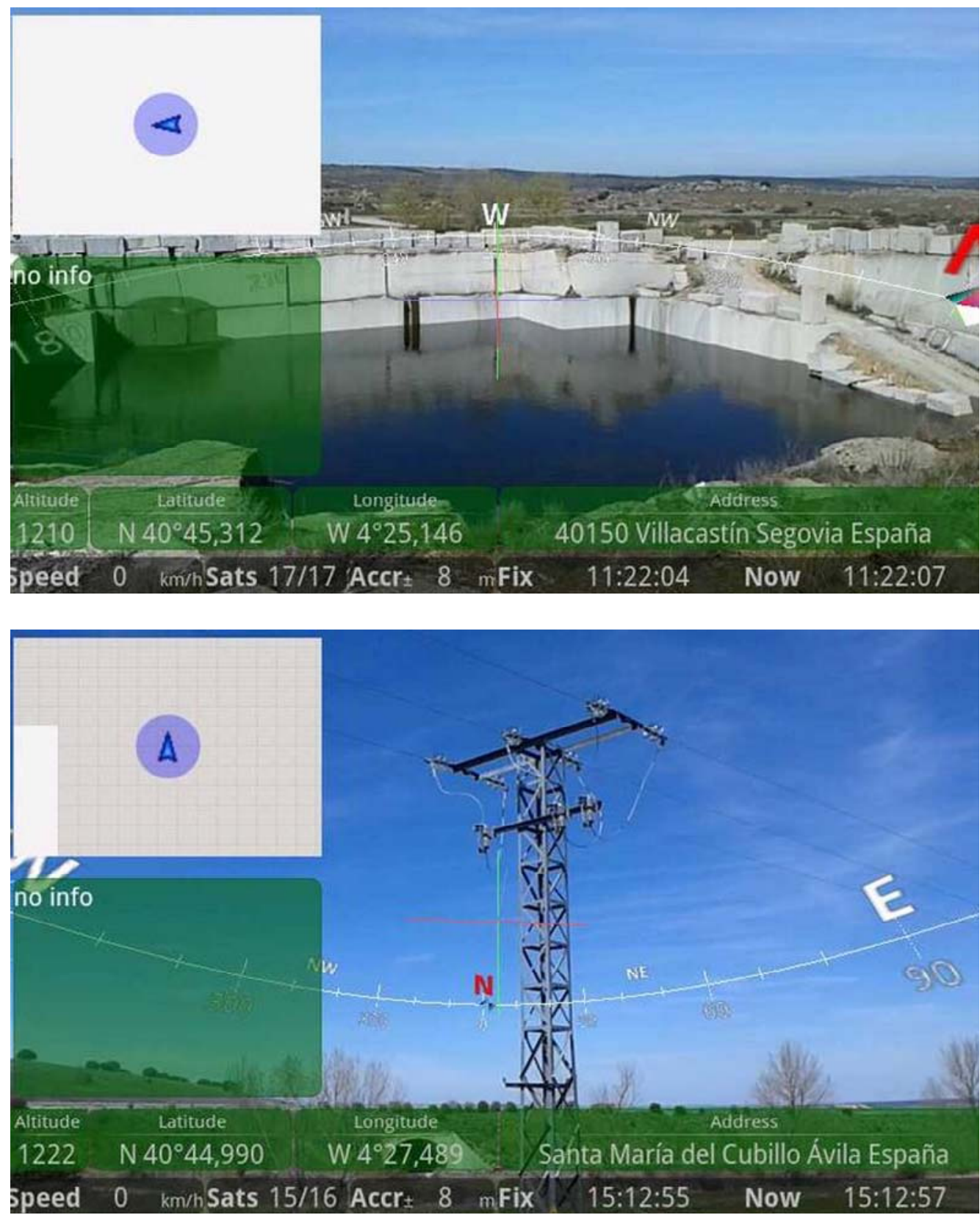

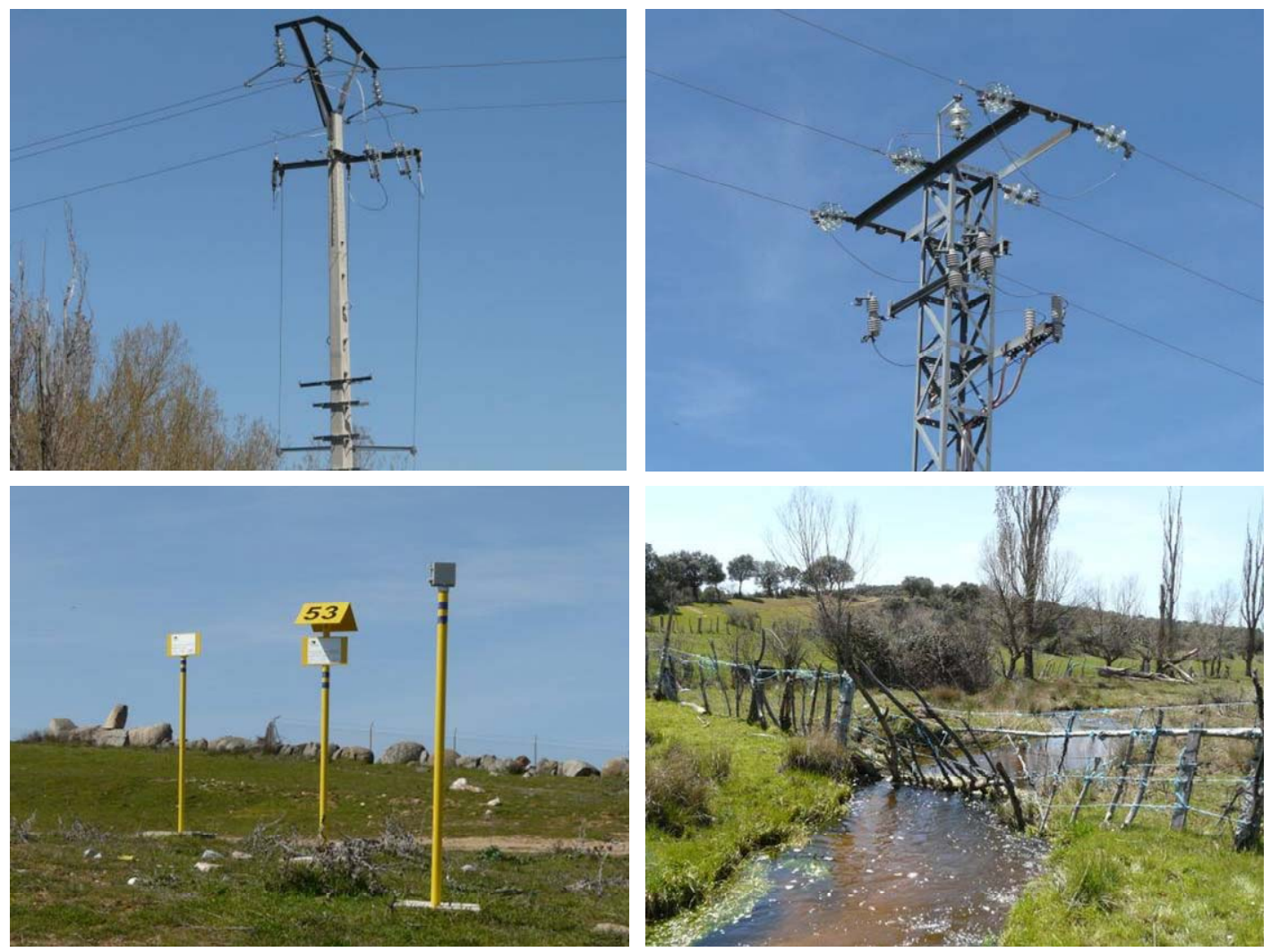

Fuente: Elaboración propia

\section{ACTUACIONES PARA FOMENTAR LA PERMEABILIDAD Y CONECTIVIDAD ECOLÓGICA}

En función de las características territoriales y ecológicas descritas, las actuaciones que se plantean tienen como fin obtener los siguientes objetivos, ligados a:

- Mejorar la conectividad entre el río Cardeña y los espacios próximos que conforman la Red Natura 2000.

- Mejorar las condiciones naturales del entorno con el fin de favorecer la permeabilidad territorial tanto de especies de fauna como de flora.

- Minimizar el efecto barrera de algunas infraestructuras tales como carreteras o tendidos eléctricos que favorecen la fragmentación del hábitat. 
De esta manera se pretenden abordar una serie de medidas a través de los siguientes criterios:

- Actuaciones que mejoren la biodiversidad y fomenten la presencia de los HICs, e indirectamente de las especies de fauna asociadas a éstos, identificadas en el ámbito de estudio.

- Actuaciones que no estén condicionadas por la propiedad del territorio donde se ejecutasen, de modo que se eviten dificultades surgidas ante la presencia de propiedad privada, por tanto se da prioridad a las actuaciones ubicadas sobre suelo público, ya sea porque sean dominio público hidráulico, vías pecuarias, servidumbres, fincas o montes de propiedad pública, etc.

A continuación, se describen cada uno de los grupos de medidas que se han identificado como más idóneas a ejecutar en los ámbitos señalados, con el fin de alcanzar los objetivos propuestos y siguiendo los criterios anteriormente establecidos. Para cada grupo de medidas se ha realizado, una descripción de la misma con los objetivos concretos que se persiguen mediante su aplicación y la localización de las actuaciones en el entorno propuesto.

\subsection{MEDIDAS PARA FOMENTAR LA PERMEABILIDAD ECOLÓGICA}

\subsubsection{LIMPIEZA DE RESIDUOS, ESCOMBROS Y BIOMASA DE LAS ÁREAS DE RIBERA}

En determinadas áreas del medio natural, especialmente en zonas periféricas de áreas urbanas o próximas a infraestructuras e industrias, se concentran algunos puntos de vertido, lo que puede implicar un "efecto llamada" a nuevos vertidos, hasta consolidarse determinadas áreas en reducidos vertederos incontrolados.

El vertido incontrolado de residuos genera distintos problemas de contaminación en función de su naturaleza, que puede degradar la calidad de las aguas fluviales o del suelo, afección a la flora y la fauna del entorno, y en general causa problemas de olores, impacto al paisaje, impedimento de la regeneración natural del territorio etc., siendo su retirada y gestión una labor dificultosa, por el hecho de que estos vertidos se suelen encontrar, en ocasiones, en lugares de difícil acceso, lo que exige un trabajo manual de cierta importancia y la utilización de maquinaria poco invasiva, en el caso de que se acceda a entornos de cierta calidad ambiental.

Entre los lugares más frecuentes en los que se encuentran este tipo de situaciones, están los sistemas fluviales, que son puntos donde se depositan habitualmente de manera incontrolada residuos o que aparecen tras ser arrastrados por la escorrentía.

Asimismo, la presencia de árboles caídos o muertos en pie genera afecciones tanto en la hidrodinámica del arroyo como en el estado fitosanitario del resto de especies, dado que pueden actuar como vector de la propagación de enfermedades y/o plagas vegetales. De igual manera, otras incidencias en la vegetación de ribera pueden venir dadas por la existencia de especies exóticas invasoras, aunque en este caso solo se ha identificado algunos ailantos (Ailanthus altissima) junto a una de las canteras 
existentes con coordenadas $40^{\circ} 45^{\prime} 190^{\prime \prime} \mathrm{N}$ y $4^{\circ} 25^{\prime} 143$ ' W. Estas se introducen o establecen en un ecosistema o hábitat natural o seminatural, siendo un agente de cambio y amenaza para la diversidad biológica nativa, ya sea por su comportamiento invasor, o por el riesgo de contaminación genética ${ }^{2}$. Por tanto, al ser especies introducidas de otras regiones cabe señalar que su presencia en un lugar del territorio ajena a su área de distribución natural, se debe a factores que son de origen humano y, en modo alguno, naturales. Su existencia se debe en ocasiones a la falta de conocimientos sobre las mismas y sobre sus efectos o impactos generados. Entre ellos pueden producir daños en la flora autóctona, toxicidad en los suelos, la fauna y para el hombre, al poder incidir sobre la salud pública, la economía e incluso el paisaje.

Para evitar estas situaciones, es necesario, incluso antes de llevar cualquier otro tipo de acción de mejora ambiental del territorio, retirar de forma controlada dichos residuos y restos de biomasa, para que posteriormente sean gestionados adecuadamente por gestores autorizados o llevados a un vertedero autorizado. Los puntos concretos en donde se plantea la aplicación de esta medida son algunos puntos de las Laderas de Cardeña y de las Cárcavas.

\subsubsection{MEJORA DE LA VEGETACIÓN DE RIBERA}

La vegetación que aparece en las riberas de ríos y arroyos desempeña una función esencial de protección de las márgenes y los cauces. Gracias a ella, por un lado, se reducen los aportes de materiales que puedan provenir por la erosión de sus márgenes $\mathrm{y}$, por otro, depura las aguas, incrementando su calidad. Asimismo, permite mantener un microclima fresco (Tabacchi et al., 2000; Gasith y Resh 1999) y desempeña un papel ecológico importante, dado que constituye un adecuado hábitat para la fauna silvestre, tanto para su asentamiento como para la cría y, en el caso de las aves, para la nidificación, por la presencia de diferentes especies vegetales que permiten lugares idóneos para ello.

Asimismo, se ha constatado que el mantenimiento de franjas de vegetación en los bordes de los ríos y arroyos facilita su funcionalidad como corredor ecológico, y permite fomentar la interconexión con diferentes ecosistemas.

Los pequeños arroyos presentes en la zona, poseen en su mayoría una cubierta vegetal formada por algunos matorrales espinosos, quedando la vegetación arbórea riparia ligada a formaciones no muy densas constituidas básicamente por sauces, álamos y fresnos en las zonas ligeramente más alejadas del cauce. Estos matorrales espinosos ofrecen cobijo a algunas especies faunísticas. Pero la intensificación de la agricultura, la carga ganadera de la zona y el consiguiente pastoreo asociado, han hecho que las formaciones vegetales se hayan reducido sensiblemente. Ello ha

${ }^{2}$ Definición establecida en el artículo 2 del Real Decreto 630/2013, de 2 de agosto, por el que se regula el Catálogo español de especies exóticas invasoras. 
supuesto la minimización de la capacidad de los arroyos de servir de corredores ecológicos, de zonas de refugio y de lugares propicios para reproducción de fauna y flora. En concreto, puede suponer un problema para algunas especies de mamíferos como los mustélidos, las ratas de agua, etc., los anfibios o en el caso de la nidificación, en especies como la oropéndola, mirlo común, ruiseñor, algunos tipos de rapaces, etc.

Figuras 17 y 18. Lugares apropiados junto al río Cadeña para realizar actuaciones de mejora en la vegetación de ribera.

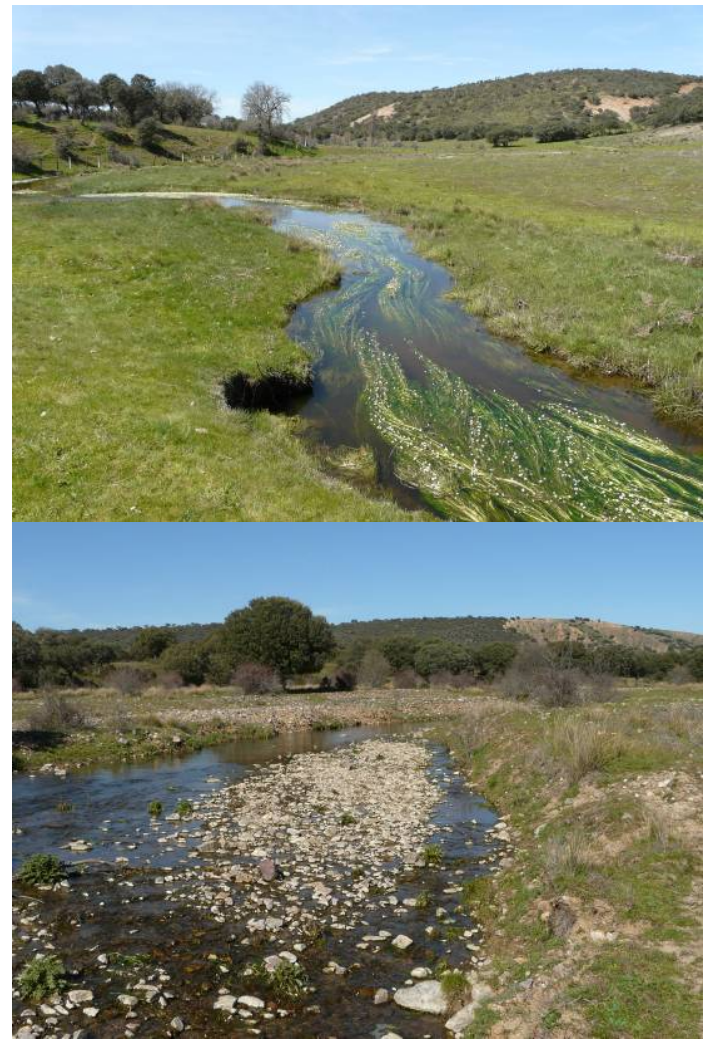

Fuente: Elaboración propia

La restauración de estas comunidades arbustivas resulta más fácil y rápida que la restauración de otros muchos espacios mediterráneos, debido a la mayor presencia y disponibilidad de agua. Su restitución dota al paisaje de mayor complejidad y variabilidad ecológica, es decir, permite que se recuperen algunas de las funciones perdidas. De esta manera, la capacidad de albergar diversidad biológica de los cursos restaurados se incrementa de forma muy notable. Por ello, se plantea la plantación, preferentemente en el otoño, de diferentes especies arbustivas y arbóreas autóctonas a lo largo de diferentes tramos del arroyo Cardeña, en especial los ubicados al norte de 
la N-110, en el área próxima a su desembocadura en el río Voltoya y en aquellos espacios con coordenadas $40^{\circ} 46^{\prime} 702^{\prime}$ ' $\mathrm{N}-4^{\circ} 27^{\prime} 870^{\prime}$ ' W y $40^{\circ} 46^{\prime} 788^{\prime}$ ' $\mathrm{N}-4^{\circ} 28^{\prime}$ 028 " W. Su disposición sería, allí donde resulte posible y siempre dentro del Dominio Público Hidráulico, en tres bandas de vegetación con especies arbóreas compuestas por sauces en las zonas más próximas al cauce, arbustivas a continuación (majuelos, juncos, endrinos y arraclanes), para finalmente terminar en el espacio más alejado del cauce con fresnos, olmos, álamos negros y arces de Montpellier. Con las especies elegidas se mejoran los Hábitats de Interés Comunitario ripícolas presentes. Por último, señalar que debido a la potencial presencia de ganado y para evitar potenciales marras, deberían implantarse tutores y cerramiento temporales para garantizar las plantaciones.

\subsubsection{PLANTACIÓN DE SETOS Y COMUNIDADES ARBUSTIVAS}

Los setos, que ejercen funciones ecológicas muy importantes, han sido uno de los elementos que han caracterizado al paisaje agrario, derivado de la necesidad de separación de fincas o lindes, y que han ido desapareciendo a medida que se ha ido intensificando la práctica agrícola y ganadera, debido, ente otros aspectos, a la mecanización agrícola que permitió la eliminación de cualquier vegetación competidora que no aportase beneficio económico directo a la explotación.

Este fenómeno de eliminación de la vegetación leñosa de los terrenos agrícolas sucedió en paralelo al abandono del cultivo de zonas marginales, formándose un medio agrario homogéneo, donde los cultivos y pastos ocupan zonas claramente delimitadas de las áreas con arbusto y bosque (González Bernáldez, 1991). A esta homogenización, se unió también la intensificación de la ganadería y la eliminación de la trashumancia.

La homogeneización del paisaje agrario y la desaparición de los setos ha provocado que los ecosistemas hayan perdido la capacidad de interconexión que aportaban, lo que ha motivado que el tránsito de muchas especies a través de grandes extensiones agrícolas o a pastos se vea imposibilitado, caso de diferentes tipos de aves (perdices, currucas, etc.) o del conejo, lo que a su vez hace que disminuya la potencial presencia de predadores, como el águila imperial ibérica por ejemplo (Harvey et al., 2005; Hass, 1995). De igual forma, muchas especies animales ligadas a medios agrarios pierden la capacidad de habitarlos o ven drásticamente reducidas sus poblaciones al perder sus lugares preferentes de cría o refugio (Keyser et al., 1998; Evans, 2004).

Por ello, debe beneficiarse los procesos de recuperación de los setos y comunidades arbustivas mediante actuaciones de plantación con anchuras cercanas a los $5 \mathrm{~m}$ con especies de matorral (retama de bolas, cantueso, tomillo, enebro y romero). De esta manera se mejoran ciertos Hábitats de Interés Comunitario presentes. Además, ante la ausencia, a veces, de arbolado más o menos próximo, es aconsejable también la plantación conjunta de ejemplares de encina y fresno, al aumentar así la 
capacidad del medio para albergar especies que puedan refugiarse o nidificar en ellas tal y como recoge en el punto 5.1.6.

Debido a la potencial presencia de ganado, las áreas elegidas para efectuar las plantaciones deben contar cerramiento temporal para garantizar la repoblación. Asimismo, se aconseja el empleo de protectores para evitar las agresiones de lagomorfos y roedores.

La plantación debe realizarse en periodos comprendidos fuera la época de cría de las especies de fauna de la zona, por lo que se considera el comienzo del otoño como la época preferente de plantación, al existir una mayor capacidad de arraigo, lo que minimiza el número de marras potencial. Concretamente las actuaciones podrían localizarse en las lindes de algunas fincas o parcelas agrarias privadas mediante convenios con propietarios y como se verá en el punto 5.1.6, junto a algunos espacios ocupados por vías pecuarias.

\subsubsection{CREACIÓN Y/O ACONDICIONAMIENTO DE PILONES DE AGUA PARA ANFIBIOS Y COMO ABREVADERO DE AGUA PARA MAMÍFEROS Y AVES}

Uno de los hábitats que mayor superficie han perdido en el pasado siglo han sido las pequeñas lagunas, charcas y humedales endorreicos (Gallego-Fernández et al., 1999; Wood et al., 2003), por lo que estos ecosistemas han pasado a ser unos de los más amenazados. Este tipo de ambientes son fundamentales para una gran cantidad de especies, en especial para los anfibios (Denton et al., 1997; Chovanec y Raab, 1997; Plissner y Haig, 2000) y para algunos tipos de aves y mamíferos por utilizarlos como bebederos o lugar de baño.

Esta pérdida o ausencia de hábitat, unida a un manejo desfavorable, ha afectado a un elevado número de especies, que ahora se encuentran en un estado de conservación negativo (Lentz y Dunson, 1999; Kirchner et al., 2003). En este sentido, actuaciones encaminadas a su recuperación, pueden ser muy importantes para la supervivencia de algunas especies, especialmente anfibios en determinados entornos, a pesar de la presencia en nuestro caso de un colector fluvial como el río Cardeña. Entre ellas, es recomendable la creación y restauración de puntos artificiales de agua sobre superficies reducidas, que sirvan para fomentar la presencia y cría de determinadas especies de anfibios y en especial tritones. En este sentido, los pilones son uno de los elementos más indicados para conseguir el fin propuesto. Estos siempre han de contar en ambos laterales con rampas que partan a nivel del suelo de uno de los bordes y finalicen en la parte superior del otro para permitir el acceso a la lámina de agua a los potenciales anfibios que puedan encontrar refugio. Esta actuación será la única que se ejecute en los pilones que se pretendan acondicionar, y es actuación imprescindible en los nuevos que se creen, que además han de presentar profundidades próximas a los $70 \mathrm{~cm}$, con el fin de mantener una lámina de agua que llegue al menos a una cota de $60 \mathrm{~cm}$, para lo cual será imprescindible que cuenten con alguna toma de agua o que sean periódicamente rellenados, sobre todo en la época estival. Con ello, además se evita el estancamiento de las aguas y se mantiene una cierta calidad en las mismas. 
Otras recomendaciones a la hora de implantar los pilones son:

- Fomento de la plantación de jucos (Juncus sp) y herbáceas como la menta poleo (Mentha puligeum) en los alrededores del pilón para crear potenciales refugios para los anfibios, fundamentalmente en el lado en el que se sitúe la rampa de acceso.

- Colocación en los alrededores de troncos o piedras del entorno.

- Situar el pilón, siempre y cuando sea posible, en zonas de sol y sombra. Por un lado el sol fomenta el crecimiento de las plantas acuáticas, mientras la sombra evita el crecimiento de algas, disminuye la temperatura y minimiza la evaporación.

- Se implantarán cerramientos en el perímetro de los pilones de nueva construcción con el fin limitar el acceso a determinadas especies que puedan alterar las condiciones morfológicas y el nivel de la lámina de agua, caso especial del ganado vacuno y ovino.

- Ejecutar la medida en épocas en que la tierra tenga cierta humedad y los arroyos posean cierto caudal, siendo el mes de noviembre una buena fecha para ubicar los nuevos pilones al igual que los que se pretende adaptar.

La localización de esta medida, además de en puntos próximos al río Cardeña, se llevaría a cabo también en el espacio con coordenadas $40^{\circ} 44^{\prime} 899^{\prime \prime}$ ' $\mathrm{N}$ y $4^{\circ} 24^{\prime} 390^{\prime}$ ' W.

\subsubsection{CREACIÓN DE REFUGIOS PARA EL CONEJO}

El conejo es la especie básica en los ecosistemas mediterráneos ibéricos al servir de alimentación a muchas especies amenazadas. Por ello, la gestión y mejora del hábitat es fundamental para incrementar o mantener su presencia al desarrollar un dinámica demográfica que permita compensar la predación y la mortandad causada por enfermedades, caza, etc., pudiendo de esta manera colonizar nuevos territorios.

La protección y/o creación de espacios aptos para la cría de los conejos de monte es una práctica habitual en aquellas áreas en las que se quiere aumentar la presencia de predadores alados por la disponibilidad de alimento. Estos lugares, denominados refugios, majanos o vivares resultan inaccesibles a los predadores, permiten el establecimiento de nuevos núcleos familiares y un aumento de la densidad de los conejos cuya presencia hace, entre otras consideraciones ecológicas, que disminuya la superficie que la vegetación herbácea natural ocupa, si bien de forma inapreciable, minimizando levemente el riesgo de incendio forestal.

Las especies más favorecidas con la disponibilidad de lugares de cría para el conejo son las aves rapaces, y en especial el águila imperial ibérica y el milano real, debido a que el corredor ecológico analizado constituye un área de nidificación, dispersión y campeo de ambas especies. 
Los criterios fundamentales para el emplazamiento de nuevas construcciones de majanos es su ubicación sobre terrenos con poca capacidad de infiltración, en una configuración de la red drenaje a favor de la pendiente. Aunque se deben instalar en zonas donde no se puedan producir inundaciones (cerros o cuerdas), es conveniente ubicarlas en las cercanías de puntos de agua, a menos de $150 \mathrm{~m}$., o en espacios próximos con presencia de matorral (retama, cantueso, tomillo o jaras) por ser un adecuado refugio natural para el conejo.

El desarrollo de la presente medida se plantea en dos etapas, la primera consiste en la creación del majano y la segunda en su protección o adaptación.

- Primera. Creación de refugio de tipo majano, mediante dos posibles técnicas. La primera de ellas es mediante la acumulación ordenada de piedras circunscritas mediante una pared circular, con parte interior en forma de laberinto, aislado del exterior y cubierto por tierra y piedras (Guil, MorenoOpo et al., 2007). La segunda de ellas, supone la implantación de palets o tablones de madera en el suelo, bien ligeramente excavado o a ras de superficie, sobre los que se depositará arenas y restos o ramas de vegetación, preferentemente de retamas o encinas, que mejora las posibilidades de cobijo de la especie.

- Segunda. Protección y adecuación de los vivares. La protección de los vivares tiene por objeto impedir o dificultar que sean excavados, mediante determinadas estructuras procedentes de subproductos silvícolas o restos de poda. Tan solo como elemento suplementario a la entrada de algunos vivares se analizará la instalación de alguna malla metálica inoxidable que permita el paso del conejo pero que a la vez impida el mismo a predadores.

Figura 19. Espacio apto para la creación de refugios para el conejo.

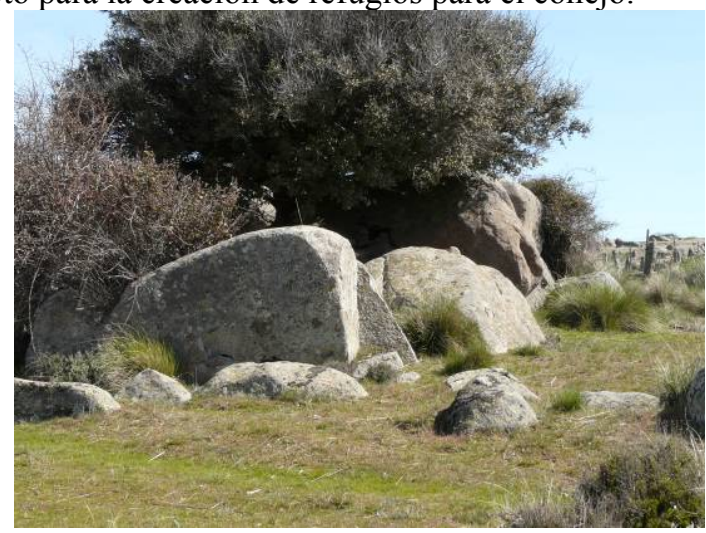

Fuente: Elaboración propia 
Los trabajos enumerados pueden realizarse durante todo el año, aunque conviene efectuarlas en el periodo de lluvias, fundamentalmente en otoño, para comprobar que se colocan en lugares secos (Guil, Moreno-Opo et al., 2007).

De manera específica, para la implantación de majanos se han identificado como posibles puntos más aptos los indicados con las siguientes coordenadas: $40^{\circ} 45^{\prime}$ ' $972^{\prime}$ ', $\mathrm{N}-4^{\circ} 25^{\prime} 015^{\prime}$ ' W, $40^{\circ} 45^{\prime} 884^{\prime}$ ' $\mathrm{N}-4^{\circ} 24^{\prime} 575^{\prime}$ 'W y $40^{\circ} 46^{\prime}, 792$ ' $\mathrm{N}-4^{\circ} 28^{\prime}$ $028^{\prime \prime} \mathrm{W}$.

\subsubsection{PLANTACIÓN DE EJEMPLARES DE ENCINA, FRESNO Y DE COMUNIDADES ARBUSTIVAS EN VÍAS PECUARIAS}

El espacio objeto de estudio se caracteriza, como es habitual en el interior peninsular de carácter mediterráneo, por serie de vegetación donde las formaciones de encinares suponen las formaciones arboladas climax, lo que dota a los ecosistemas de mayor estabilidad ante posibles perturbaciones y una mayor madurez funcional.

La presencia de encinares, ya sea como bosque o de forma adehesada, conlleva la existencia de una rica y diversa fauna, tanto de mamíferos como de aves, algunas tan relevantes como el águila imperial ibérica.

Por otro lado, el fresno sirve como soporte de nidificación para algunas de las aves rapaces existentes en el territorio, caso del milano real, el ratonero o el águila calzada. A ello se suma la presencia de matorral que sirve de cobijo para algunas especies de aves, mamíferos y reptiles.

El principal objetivo de esta medida es el aumento de la cobertura arbolada y de matorral en aquellos espacios en los que se ha identificado que es escasa, sin disminuir la capacidad de acogida para la fauna del medio forestal.

La regeneración de la superficie arbolada permite mejorar el hábitat de la fauna forestal, recuperando áreas para la nidificación futura de determinadas especies ligadas a este medio, como aumentar la capacidad del medio para albergar especies que se pueden refugiar en ellas, ya sean aves o mamíferos de diferente tamaño, desde el lirón careto, la comadreja, o la gineta cuando el árbol alcanza una determinada edad.

Las áreas elegidas para efectuar las plantaciones deben presentar cerramiento temporal para garantizar la repoblación, debido a la potencial presencia de ganado. Igualmente, es aconsejable el uso de protectores para evitar las agresiones de lagomorfos y roedores.

La plantación, en la que en función del espacio disponible el arbolado y el matorral puede presentarse y combinarse en hileras o en tresbolillo, debe llevarse a cabo en periodos comprendidos fuera la época de cría de las especies de fauna de la zona, por lo que el comienzo del otoño se considera como la época preferente, al ser mayor capacidad de arraigo y minimizarse el número de marras potencial. Tienen como finalidad potenciar los siguientes Hábitats de Interés Comunitario, el 6310, 91B0, 9340, 5210, 5330 y en menor medida el 4090. 
Para la plantación de estas especies (en el caso de los matorrales las descritas en el apartado 5.1.3) se han elegido como espacios adecuados por su carácter público, el entorno de las vías pecuarias (principalmente Cañadas Real Leonesa Oriental y de Valdeherreros) en concreto en los entornos situados con las coordenadas siguientes: $40^{\circ} 45^{\prime} 356^{\prime \prime} \mathrm{N}-4^{\circ} 24^{\prime} 226^{\prime}$ ' W, 40 46' $119^{\prime}$ ' $\mathrm{N}-4^{\circ} 25^{\prime} 153^{\prime}$ ' W, $40^{\circ} 45^{\prime} 877^{\prime}$ ' $\mathrm{N}$ $4^{\circ} 24^{\prime} 806^{\prime}, \mathrm{W}, 40^{\circ} 45^{\prime} 570^{\prime}$ ' $\mathrm{N}-4^{\circ} 24^{\prime} 514^{\prime}, \mathrm{W}, 40^{\circ} 44^{\prime} 129^{\prime}$ ' $\mathrm{N}-4^{\circ} 24^{\prime} 193$ ' $\mathrm{W}$, $40^{\circ} 43^{\prime} 782^{\prime}$ ' $\mathrm{N}-4^{\circ} 23^{\prime} 894^{\prime}$ ' W, $40^{\circ} 46^{\prime} 620^{\prime}$ ' $\mathrm{N}-4^{\circ} 26^{\prime} 077^{\prime}$ ' W y $40^{\circ} 45^{\prime} 783^{\prime \prime} \mathrm{N}$ $-4^{\circ} 30^{\prime} 329^{\prime \prime} \mathrm{W}$.

Figuras 20 y 21. Lugares aptos para la plantación de ejemplares de encina, fresno y de comunidades arbustivas.
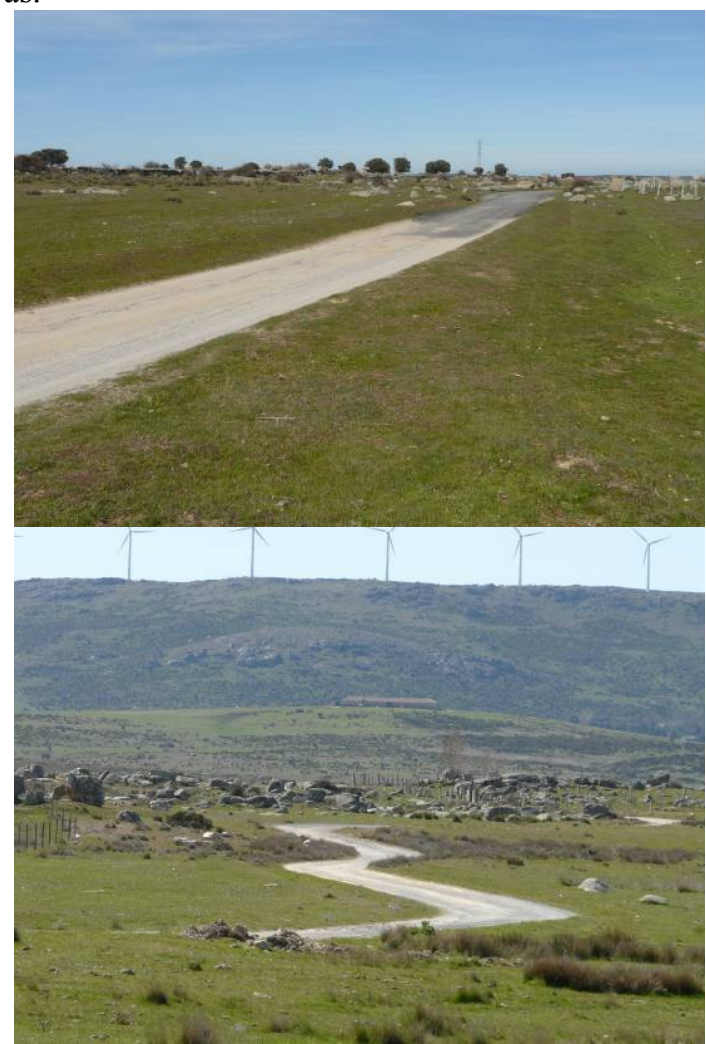

Fuente: Elaboración propia 


\subsubsection{MEDIDAS PARA ATENUAR LA AFECCIÓN A LA AVIFAUNA A CAUSA DE LOS TENDIDOS ELÉCTRICOS}

Las líneas eléctricas pueden suponer un riesgo para la avifauna presente en el territorio propuesto como corredor ecológico. Los accidentes de aves en las conducciones eléctricas se han convertido en una de las principales causas de mortalidad, tal y como afirma el Libro Rojo de las Aves de España. La tipología de accidentes se dividen, como es conocido, principalmente en dos categorías: electrocuciones y colisiones con los tendidos eléctricos.

Las electrocuciones se generan principalmente cuando las aves, al utilizar los tendidos y torretas como lugares de descanso, posaderos o como oteaderos, tocan al mismo tiempo dos cables conductores o un cable y la propia torreta, provocando una derivación de corriente a través de su cuerpo. Este tipo de riesgo se acrecienta en los tendidos eléctricos menores de $66 \mathrm{Kv}$, debido a que la distancia entre conductores y cruceta es más pequeña, siendo de esta manera, más probable el contacto antes mencionado.

Las colisiones, se generan cuando el ave, en su vuelo, no observa los cables y muere al colisionar de forma brusca con ellos, especialmente en aquel situado en la parte superior que aparece en el caso de los tendidos medios o grandes, al ser más fino. De forma general, las especies que más propensión tienen a sufrir dichos accidentes, son aquellas de un elevado peso corporal y gran envergadura alar que posean generalmente un vuelo con escasa capacidad de maniobra y las que poseen un comportamiento gregario en la formación de grandes concentraciones de ejemplares. Asimismo, la situación de la línea, en relación a su visibilidad, ya sea por su ubicación respecto a la topografía, la presencia de elementos que la oculten como masas de vegetación, etc., además de las condiciones generales atmosféricas, son factores que influyen igualmente en la mortandad, independientemente de la especie de avifauna.

El objetivo principal de esta medida, es reducir la mortalidad de las aves, mejorando la conectividad del corredor para este tipo de especies. Para ello, se han identificado, a través del trabajo de campo, aquellos tendidos eléctricos que carecen de medidas anticolisión para la avifauna y se han señalado con GPS las coordenadas de algunos de los apoyos más conflictivos, siendo prioritaria su modificación bien por otro tipo bóveda o tresbolillo, o la modificación en el diseño de las crucetas de los apoyos. Es el caso de los situados en la dehesa de Tabladillo, en algunos de la línea eléctrica que discurre desde Aldeavieja hasta pasado una antigua estación de servicio, así como en otros cuyas coordenadas se corresponden con: $40^{\circ} 46^{\prime} 507^{\prime}$ ' $\mathrm{N}-4^{\circ} 25^{\prime}$ $604^{\prime}$ ' W, $40^{\circ} 46^{\prime} 500^{\prime \prime} \mathrm{N}-4^{\circ} 25^{\prime} 877^{\prime} ' \mathrm{~W}, 40^{\circ} 46^{\prime} 788^{\prime}$ ' $\mathrm{N}-4^{\circ} 28^{\prime} 028^{\prime}$ ' W y $40^{\circ}$ $45^{\prime} 613^{\prime}, \mathrm{N}-4^{\circ} 30^{\prime} 019^{\prime}$ ' W. 
Figuras 22 y 23. Detalle de apoyos tipo bóveda que minimizan los riesgos de electrocución en las aves en el área de estudio (proximidades a la N-110 y al norte de Blascoeles).

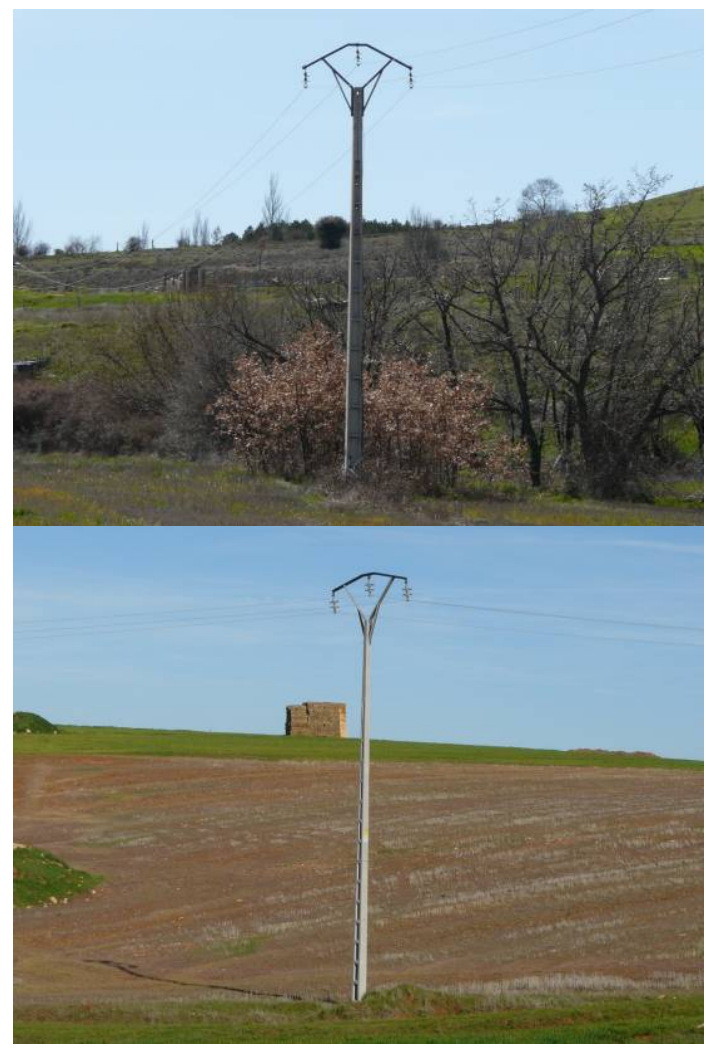

Fuente: Elaboración propia.

En cuanto a la implantación de dispositivos anticolisión, su finalidad es incrementar la visibilidad de los cables del tendido por parte de las aves mediante la implantación de uno de los dos posibles elementos siguientes. El primero de ellos son las espirales salvapájaros que son bandas que se instalan alrededor de los conductores, especialmente del más fino si lo hubiere por su menor visibilidad, de forma que sirva de elemento disuasorio para las aves. Se recomienda que dichas espirales sean de color rojo u otros colores llamativos sobre el paisaje con materiales que permitan una alta durabilidad próxima o superior a 10 años y un diámetro aproximado de $30 \mathrm{~cm}$. La colocación de dichas espirales tienen que realizarse de tal forma que exista una distancia entre ellas como máximo de $5 \mathrm{~m}$.

El segundo elemento posible son las tiras negras que constan de dos tiras de color negro de neopreno (material que asegura una gran durabilidad) de dimensiones aproximadamente de $5 \times 35 \mathrm{~cm}$., que están cruzadas y sujetas entre sí por una grapa de 
poliuretano con cintas luminiscentes. En este tipo de sistemas se recomienda que la instalación se haga de tal forma que el efecto visual equivalente sea de una señal cada $10 \mathrm{~m}$.

La implantación de una de estas dos opciones es necesaria en el tendido de $132 \mathrm{kV}$ que parte desde Ávila capital en dirección NE, hasta la localidad de Lastras de Pozo (Segovia), atravesando el espacio de estudio en áreas como la Cañada de Valdeherreros o el propio río Cardeña en el punto con coordenadas $40^{\circ} 47^{\prime} 050^{\prime \prime} \mathrm{N}$ y $4^{\circ} 28^{\prime} 526^{\prime \prime}$ W.

Figuras 24 y 25. Detalle de sistemas salvapájaros y antielectrocución implantados en el tendido situado en las inmediaciones del camino cercano al arroyo Valdelacasa, afluente del río Cardeña y con ausencia de salvapájaros (tendido $>110 \mathrm{kV}$ en dirección NE).

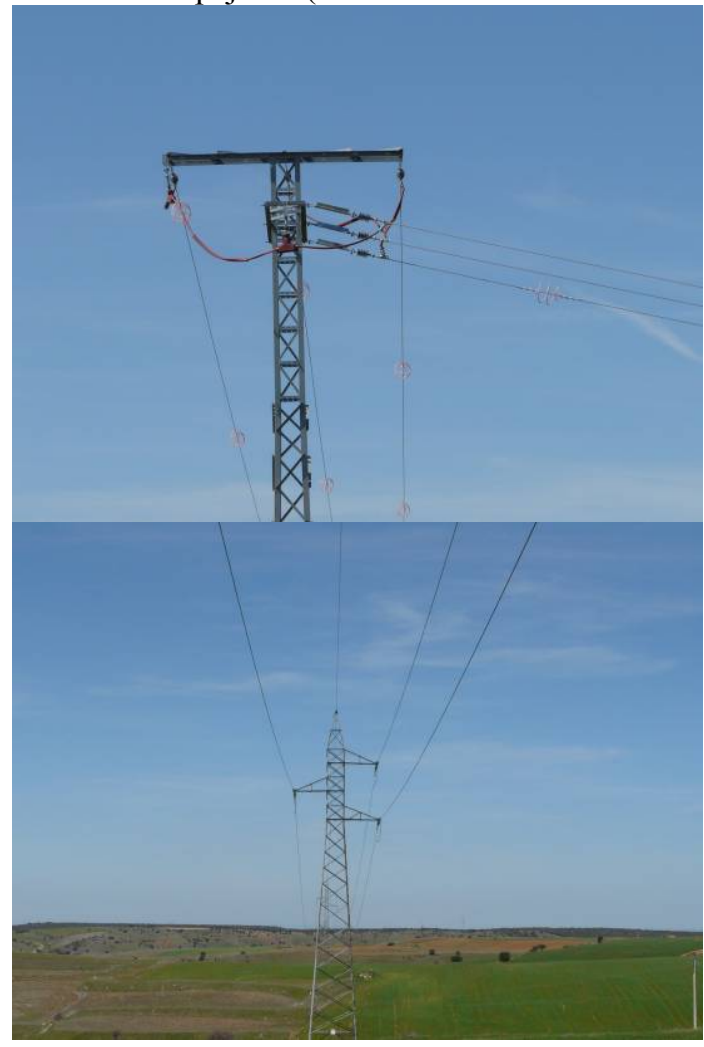

Fuente: Elaboración propia. 


\subsubsection{IMPLANTACIÓN DE CAJAS NIDO PARA LAS AVES INSECTÍVORAS, RAPACES Y QUIRÓPTEROS}

Las cajas nido para aves insectívoras, rapaces o murciélagos proporcionan a los animales un lugar más seguro para criar o refugiarse, mejorando el confort térmico, la defensa contra parásitos y la disminución de la predación. Además, son muy útiles cuando existe escasez de lugares adecuados donde ubicar un nido o donde refugiarse, lo que favorece la reproducción y el éxito de la misma en algunas especies, permitiendo de esta manera el aumento y consolidación de las poblaciones existentes.

En el caso de las aves insectívoras su presencia favorece la lucha contra las plagas originadas por pequeños invertebrados de los que se alimentan. De igual manera, los murciélagos son beneficiados por tener una dieta básicamente insectívora, llegando a consumir según los estudios del zoólogo ruso Korskof 60.000 mosquitos durante los meses de primavera y verano. La escasez de lugares adecuados para nidificar o para hibernar ha provocado una alarmante disminución de estos animales, por lo que con la instalación de cajas nido se pueden mejorar las densidades de quirópteros, tanto en medios urbanos como forestales.

En cuanto a las aves rapaces, aunque no es tan común su nidificación en este tipo de estructuras, el fomento de estos elementos se realiza fundamentalmente en aquellos lugares que no presentan muchos espacios en los que poder anidar, pero en los cuales si existe una disponibilidad trófica relativamente abundante o suficiente para albergar poblaciones estables de estas aves amenazadas.

De esta manera se considera prioritario proteger y fomentar la presencia de algunas especies de aves insectívoras (páridos en gran parte), rapaces y quirópteros, potenciando la disponibilidad de medios en los que poder llevar a cabo la nidificación.

En el caso de las aves rapaces, dado el territorio existente, con alternancia de algunos espacios aclarados con otros con presencia de arbolado de cierta densidad, las especies más beneficiadas con la implantación de esta medida serían el cernícalo vulgar y la lechuza común, debido en el caso de esta última a la potencialidad del lugar de albergar a la especie y a la relativa escasa presencia de edificaciones abandonadas en la zona.

Para lograr los objetivos propuestos se instalarían diferentes modelos de cajas anidaderas con dimensiones y diámetros de agujero de entrada variados $(32 \mathrm{~mm}, 26$ $\mathrm{mm}$, etc.) adaptados a las siguientes grupos o especies de aves: páridos, petirrojo, colirrojo tizón, trepador azul, carraca, papamoscas cerrojillo, gorrión molinero etc., y también a determinadas rapaces como el cernícalo vulgar o la lechuza común.

Si bien cualquier época del año es óptima para la instalación de estas estructuras, la más propicia es la estación otoñal, dado que es invierno cuando empieza a existir una mayor ocupación hasta mediados de verano.

La instalación de las cajas nido de aves de mayor tamaño se colgarán a mayor altura. La ocupación puede ser más rápida si se instala una capa de virutas de madera o serrín en el fondo de la caja. 
El agujero de entrada normalmente se recomienda que esté mirando hacia el sureste, pero esto no es necesario si el lugar donde se instala la caja está resguardado de los vientos dominantes.

Las cajas nido para rapaces podrán situarse en postes de hormigón de tendidos eléctricos instalándose a una altura igual a las $2 / 3$ de la altura total de apoyo, si bien en ningún caso se situarán a más de $8 \mathrm{~m}$. de altura ni a menos de $3 \mathrm{~m}$. de los conductores. En estos casos, no es recomendable insertar nada en su interior, dado que dichas aves prefieren aportar los materiales necesarios para construir el nido cada año.

Figura 26. Modelo de caja nido para aves.

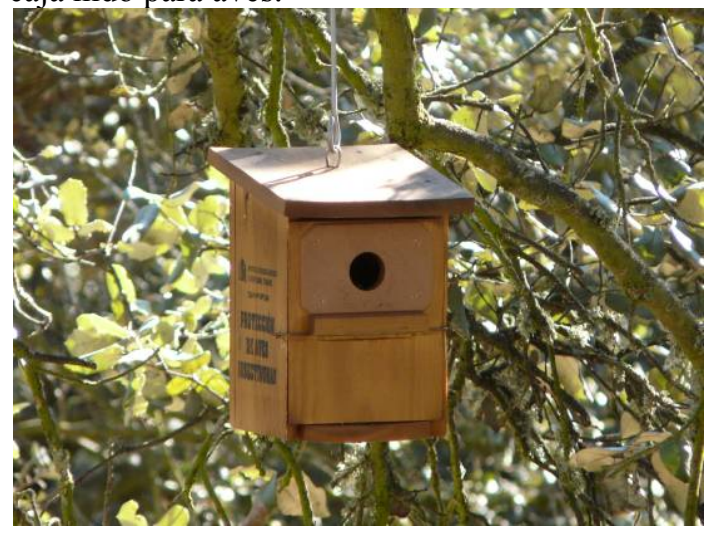

Fuente: Samantha Yablonovich Fernández.

Del mismo modo, se instalarían cajas especialmente diseñadas para la nidificación y refugio de quirópteros forestales. Inicialmente, se colocarían entre 3 y $6 \mathrm{~m}$. de altura en zonas preferiblemente orientadas hacia el sur para propiciar una alta temperatura interior en el invierno. Se proponen grupos de 3 cajas más o menos próximas para permitir que los murciélagos puedan cambiar con facilidad de refugio cuando sea necesario.

\subsubsection{MEJORA DE LA CALIDAD DE LAS AGUAS Y DEL DOMINIO PÚBLICO HIDRAÚLICO}

La presencia en el dominio público hidráulico (Zonas de Servidumbre o Policía) del río Cardeña de canteras hace que esta franja de terreno alrededor del cauce del río y la calidad de las aguas pueda sufrir una considerable degradación a consecuencia de la alteración del terreno que supone la actividad extractiva que se desarrolla. Esta invasión supone que no se cumpla con lo establecido en la Directiva 2000/60/CE del Parlamento Europeo y del Consejo, de 23 de octubre de 2000, por la que se establece un marco comunitario de actuación en el ámbito de la política de aguas, conocida 
como Directiva Marco del Agua, y con la normativa estatal que traspone esta normativa europea, el Real Decreto Legislativo 1/2001, de 20 de julio, por el que se aprueba el texto refundido de la Ley de Aguas (sujeto a varias modificaciones posteriores), y más concretamente con lo indicado dentro del Título V "De la protección del dominio público hidráulico y de la calidad de las aguas continentales" en la totalidad del artículo 92 "Objetivos de la protección", pero sobre todo en el artículo 92 bis "Objetivos medioambientales" en el que se dice:

1. Para conseguir una adecuada protección de las aguas, se deberán alcanzar los siguientes objetivos medioambientales:

a. Para las aguas superficiales:

a'.Prevenir el deterioro del estado de las masas de agua superficiales. b'.Proteger, mejorar y regenerar todas las masas de agua superficial con el objeto de alcanzar un buen estado de las mismas.

c'.Reducir progresivamente la contaminación procedente de sustancias prioritarias y eliminar o suprimir gradualmente los vertidos, las emisiones y las pérdidas de sustancias peligrosas prioritarias.

Es por tanto esencial cumplir con lo establecido en la legislación vigente mediante la realización del correspondiente deslinde del río, la realización de analíticas periódicas de las aguas para ver la evolución de su calidad y la vigilancia a cargo de la guardería fluvial de la Confederación Hidrográfica del Duero del dominio público para evitar invasiones del mismo o la realización de usos ajenos a derechos, concesiones o usos previamente autorizados. Para esto último, se antoja esencial la disposición de un mayor personal ante la escasez existente actualmente y la no renovación de usos de fuerte impacto ambiental como las canteras, así como la no concesión de otros nuevos que puedan causar similares afecciones.

\section{CONCLUSIONES}

Tanto por lo recogido en la Ley 42/2007, de 13 de diciembre, del Patrimonio Natural y de la Biodiversidad, como por la importancia que para las especies supone la conectividad de las poblaciones, se hace necesario el favorecer la existencia de corredores ecológicos al constituir un elemento fundamental en cualquier política ambiental que se pretenda llevar a cabo. Estas áreas de conectividad ecológica deben servir para mejorar los objetivos de conservación tanto de LICs, ZECs, ZEPAs al unir y posibilitar en estos espacios incluidos en la Red Natura 2000, la presencia de una mayor diversidad de especies o el aumento de las poblaciones especialmente de aquellas que presenten un claro déficit de individuos, especialmente si están protegidas y/o son endémicas. 
El ámbito del río Cardeña constituye un territorio no solo en donde confluyen dos ámbitos administrativos diferentes (provincias de Ávila y Segovia), sino un área en la que en este caso un río sirve como eje vertebrador para las especies existentes en los LICs y ZEPAs Encinares de los ríos Adaja y Voltoya y Valles del Voltoya y el Zorita.

Pero para lograr que este y otros espacios "puente" sirvan como nexo de unión de áreas de mayor valor ecológico, es necesario actuar y fomentar acciones que protejan y mejoren los hábitats de las especies florísticas y faunísticas presentes, básicamente por el carácter móvil de los animales. Para ello es fundamental en primer lugar, mediante un exhaustivo trabajo de campo y de gabinete, el analizar todos los componentes del área de estudio, con especial interés en aquellos de tipo biótico y antrópico, pues solamente de esta manera se tendrán las bases sólidas necesarias para implantar las actuaciones y medidas más convenientes a desarrollar. Ejemplo de ellas en el caso que nos ocupa y teniendo en cuenta su relativo bajo coste, son la mejora de todos los componentes del dominio público del río, la plantación de diferentes especies florísticas, la implantación de cajas nido y majanos, la corrección de tendidos eléctricos o la creación y/o acondicionamiento de pilones de agua para anfibios o como lugar de abrevadero para mamíferos y aves.

Al efectuarse las acciones descritas en el medio rural debe resaltarse, que además de concienciar a los habitantes allí presentes de los beneficios que supone la mejora ecológica del territorio no solamente para las especies existentes, es necesario involucrarles en su conservación, y que mejor manera de hacerlo si ello también supone una mejora socioeconómica, mediante el empleo de mano de obra de la zona en las mediadas a implantar o el incremento de la actividad turística. A pesar del contexto de crisis económica actual y de que la conservación es vista como algo secundario en muchas ocasiones, por la necesidad de actuar a corto plazo, las mejoras territoriales a medio y largo plazo que suponen la creación de corredores ecológicos, hacen que deban ser prioritarias en las políticas ambientales que se desarrollen.

\section{BIBLIOGRAFÍA}

BARTOLOMÉ, C, ÁLVAREZ JIMÉNEZ, J, VAQUERO, J, COSTA, M, CASERMEIRO, M, GIRALDO, J \& ZAMORA J (2005). Los Tipos de Hábitats de Interés Comunitario de España. Guía Básica. Ministerio de Medio Ambiente.

BENNETT, A. F. (1999): Linkages in the Landscape. The role of corridors and connectivity in wildlife conservation. IUCN, Gland, Switzerland and Cambridge, UK.

CHOVANEC A \& RAAB R (1997). Dragonfiles (Insecta, Odonata) and the ecological status of newly created wetlands - examples for long-term bioindication programmes. Limmologica 27 (3-4), 382, 392.

DENTON J.S., HITCHINGS S.P., BEEBEET T.J \& GENT A (1997). A recovery Program for the Natterjack toad (Bufo calamita) in Britain. Conservation Biology 11 (6), 1329-1338. 
EVANS, K.L (2004). The potencial for interactions between predation and habitat change to use population declines of farmland birds. Ibis 146 (1), 1-13.

FAHRIG, L (2003). Effects of habitat fragmentation on biodiversity. Annu Rev Ecol Syst 34:487-515.

FERNÁNDEZ, J. (2000). Avance del Atlas de Quirópteros de Castilla y León. Junta de Castilla y León. Consejería de Medio Ambiente. Informe inédito.

GALLEGO FERNÁNDEZ J.B., GARCÍA-MORA M.R \& GARCÍA NOVO, F (199). Small wetlands lost: a biological conservation Hazard in Mediterranean landscapes. Enviromental Conservation 26, 190-199.

GASITH, A \& RESH V.H, (1999). Streams in Mediterranean climate regions: Abiotic Influences and Biotic Responses to Predictable Seasonal Events. Annual Review of Ecology and Systematics 30, 51-81.

GONZÁLEZ BERNÁLDEZ, F (1991). Ecological consequences of the abandonment of tradicional land use systems in central Spain. Opinions Mediterranneenes 15, 23-29.

GUIL, F \& MORENO-OPO, R, (Coords), (2007). Catálogo de buenas prácticas para la gestión del hábitat en Red Natura 2000: bosque y matorral mediterráneos. Una propuesta de actuaciones financiables en Red Natura. Fundación CBD-Hábitat. Madrid.

GURRUTXAGA SAN VICENTE, M \& LOZANO VALENCIA, P.J (2008). Evidencias sobre la eficacia de los corredores ecológicos: ¿Solucionan la problemática de la fragmentación de hábitats? Observatorio Medioambiental Vol 11 (2008). pp 171-183.

GURRUTXAGA SAN VICENTE, M (2005). Red de Corredores Ecológicos de la Comunidad Autónoma de Euskadi. Documento de Síntesis. Departamento de Medio Ambiente y Ordenación del Territorio. Gobierno Vasco.

HARVEY C.A., VILLNUEVA C., VILLACÍS J., CHACÓN M., MUÑOZ J., LÓPEZ M.V., IBRAHIM K.M., GÓMEZ H., TAYLOR R.H., MARTÍNEZ T., NAVAS A., SAENZ J., SÁNCHEZ G., MEDINA A., VILCHEZ S., HERNÁNDEZ J.M., PEREZ A., RUUIZ F., LÓPEZ F., LANG I \& SINCLAIR F.L (2005). Contribution of live fences to the ecological integrity of agricultural landscapes. Agriculture, Ecosystems and Enviroment 11, 200-230.

HASS C. A (1995). Dispersal and use of corridors by birds in wooded patches on an agricultural landscape. Conservation Biology 9 (4), 845-854.

JON M. CONRAD, CARLA P. GOMES, WILLEM-JAN VAN HOEVE, ASHISH SABHARWAL, JORDAN F. SUTER (2012). Wildlife corridors as a connected subgraph problem, Journal of Environmental Economics and Management, Volume 63, Issue 1, January, Pages 1-18.

KEYSER A.J., HILL G.E \& SOEHREN E.C (1998). Effects of Forest fragment Size, Nest Density, and Proximity to Edge on the Risk of Predation to Ground-Nesting Passerine Birds. Conservation Biology 12 (5), 986-994.

KIRCHNER F., FERDY J.-B., ANDALO C., COLAS B., MORET J (2003). Role of Corrridors in Plant Dispersal: an Example with the Endangered ranunculus modif lorus. Conservation Biology 17 (2), 401-410. 
LENTZ K.A \& DUNSON W.A (1999). Distinguishing characteristics of temporary pond habitat of endagered northeastern bulrush, Scirpus ancistrochaetus. Wetlands 19 (1), 162-167.

LÓPEZ GONZÁLEZ, F. J.; LIZANA AVIA, M; SILLEROS PABLOS, N. Y PÉREZ MELLADO, V. (2000). Primer Informe del Convenio entre la Asociación Herpetológica Española y la Junta de Castilla y León (Inédito).

LÓPEZ GONZÁLEZ, G (2002). Guía de los árboles y arbustos de la Península Ibérica y Baleares. Ediciones Mundi Prensa.

LUELL, B., BEKKER, G.J., CUPERUS, R., DUFEK, J., FRY, G., HICKS, C., HLAVÁC, V., KELLER, V., B., ROSELL, C., SANGWINE, T., TORSLOV, N., B. LE MAIRE, (EDS) (2005). Fauna y tráfico: manual europeo para la identificación de conflictos y el diseño de soluciones. 166 pp. Organismo Autónomo de Parques Nacionales.

MARTÍ, R. \& J. C. DEL MORAL (eds.) (2003). Atlas de las aves reproductoras de España, DGCN-SEO/BirdLife, Madrid.

MCEUEN, A. (1993): The wildlife corridor controversy: a review. Endangered Species Update 10: 1-7.

MINISTERIO DE MEDIO AMBIENTE Y MEDIO RURAL Y MARINO (2010). Prescripciones técnicas para la reducción de la fragmentación de hábitats en las fases de planificación y trazado. Documentos para la reducción de la fragmentación de hábitats causada por infraestructuras del transporte, número 3. O.A. Parques Nacionales. Ministerio de Medio Ambiente y Medio Rural y Marino. 145 pp. Madrid.

NICOLA CLERICI, PETER VOGT (2013).Ranking European regions as providers of structural riparian corridors for conservation and management purposes, International Journal of Applied Earth Observation and Geoinformation, Volume 21, April, Pages 477-48.

NOSS, R. F. (1993): Wildlife corridors. En: Smith, D.S. y Hellmond, P.C. (eds). Ecology of greenways. Design and function of linear conservation areas. University of Minnesota Press, Minneapolis: 43-68.

NOTICIAS JURÍDICAS (2012). Legislación Ley 42/2007, de 13 de diciembre, del Patrimonio Natural y de la Biodiversidad. http://noticias.juridicas.com/base_datos/Admin/142-2007.html [Consultado el 2007-2012].

NOTICIAS JURÍDICAS (2012). Legislación Real Decreto Legislativo 1/2001, de 20 de julio, por el que se aprueba el texto refundido de la Ley de Aguas. http://noticias.juridicas.com/base_datos/Admin/rdleg1-2001.html [Consultado el 10-10-2012].

OLMEDA LATORRE, C, DEL BARRIO ESCRIBANO, G., GARCÍA CALVO, D., BARRIOS AQUINO, V., SÁNCHEZ PÉREZ, E., SIMÓN ZARZOSO, J.C., CLIMENT VALIENTE, M., CARREÑO FRUCTUOSO, M.F., PÉREZ IBARRA, I., MÁRQUEZ BARRASO S., RUIZ MORENO, A (2007). Identificación y Diagnóstico de la Red de Corredores Ecológicos de la Región de Murcia. 
Consejería de Desarrollo Sostenible y Ordenación del Territorio. Región de Murcia.

PALOMO L. J, GISBERT, J \& BLANCO, J. C (2007) EDITORES. Atlas y Libro Rojo de los mamíferos terrestres de España. Ministerio de Medio Ambiente. Dirección General para la Biodiversidad, Sociedad Española para la Conservación y Estudio de los Murciélagos (SECEMU) y Sociedad Española para la Conservación y Estudio de los Mamíferos (SECEM).

PAREDES, V \& BALLESTEROS, F (2008). Guía de las plantas de los ríos y riberas de la cuenca del Duero. Ministerio de Medio Ambiente y Medio Rural y Marino.

PATRICK R. HUBER, FRASER SHILLING, JAMES H. THORNE, STEVEN E. GRECO (2012). Municipal and regional habitat connectivity planning, Landscape and Urban Planning, Volume 105, Issues 1-2, 30 March, Pages 15-26.

PLEGUEZUELOS, JUAN M., MÁRQUEZ, R \& LIZANA, M (2002). Atlas y Libro Rojo de los anfibios y reptiles de España. Ministerio de Medio Ambiente.

PLISSNER, J. H., \& HAIG, S. M. (2000). Status of a broadly distributed endangered species: results and implications of the second International Piping Plover Census. Canadian Journal of Zoology, 78(1), 128-139.

ROY, A., SHANTHALA, B.S., DEVI, DEBNATH, B., MURTHY, M.S.R. (2010). Geospatial model for identification of potential ecological corridor in Orissa. Special issue on Biodiversity and Landscape Ecology. Journal of the Indian Society of Remote Sensing.

SANZ ELORZA, M, DANA SÁNCHEZ, ELÍAS D \& SOBRINO VESQUIRAS, E (2004). Atlas de las Plantas Alóctonas Invasoras de España. Ministerio de Medio Ambiente.

SANZ-ZUASTI, J. Y VELASCO, T. (1999). Guía de las Aves de Castilla y León.

SANZ-ZUASTI, J. Y VELASCO, T. (2000). Propuesta de la Consejería de Medio Ambiente para la declaración de Zonas de Especial Protección para las Aves (ZEPAs) en Castilla y León. Informe Final (Inédito). Consejería de Medio Ambiente. Junta de Castilla y León.

SOTELO NAVALPOTRO, J. A (2007). Medio Ambiente, Desarrollo y Sostenibilidad: Modelos y Políticas de actuación contradictorias: entre lo global y lo local, Oxford University Press.

TABACCHI, E., LAMBS, L., GUILlOY, H., PLANTY-TABACCHI, A.M., MULLER, E \& DECAMPS, H (2000). Impact of riparian vegetation on hydrological processes. Hydrological Processes 14 (16), 2959-2976.

TILLMANN, J.E. (2005). Habitat Fragmentation and Ecological Networks in Europe. GAIA - Ecological Perspectives for Science and Society 14: 119-123. 